\title{
Base-mediated Intramolecular Cyclization of $\alpha$-Nitroethylallenic Esters as a Synthetic Route to 5-Hydroxy-3-pyrrolin-2-ones
}

Narendra Kumar Vaishanv, ${ }^{\dagger}$ Mohd Khalid Zaheer, $^{\dagger}$ Sandeep Kumar, $^{\dagger}$ Ruchir Kant, $^{\S}$
and Kishor Mohanan ${ }^{\dagger, \neq, *}$

${ }^{\dagger}$ Medicinal \& Process Chemistry Division and ${ }^{\S}$ Molecular and Structural Biology Division, CSIR-Central Drug Research Institute, BS-10/1, Sector 10, Jankipuram extension, Sitapur Road, P.O. Box 173, Lucknow 226031, India

${ }^{\ddagger}$ Academy of Scientific and Innovative Research, Ghaziabad-201002, India

kishor.mohanan@cdri.res.in

SUPPORTING INFORMATION

Contents:

1. X-ray data of compounds $2 f$ and $4 e \quad S 2$

2. Copies of ${ }^{1} \mathrm{H}$ and ${ }^{13} \mathrm{C}$ spectra for all compounds S5 


\section{X-Ray Data Collection and Structure Refinement Details for compound 2f:}

A good quality single crystal of size $0.37 \times 0.20 \times 0.10 \mathrm{~mm}$, was selected under a polarizing microscope and was mounted on a glass fiber for data collection. Single crystal $X-$ ray data for compound $\mathbf{2 f}$ were collected on the Rigaku Kappa 3 circle diffractometer equipped with the AFC12 goniometer and enhanced sensitivity (HG) Saturn724+ CCD detector

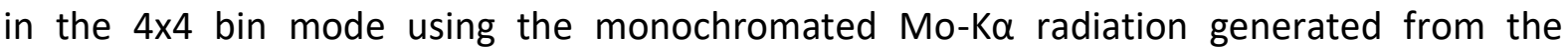
microfocus sealed tube MicroMax-003 X-ray generator equipped with specially designed confocal multilayer optics. Data collection was performed using $\omega$-scans of 0.50 steps at 293(2) K. Cell determination, data collection and data reduction was performed using the Rigaku CrystalClear-SM Expert 2.1 b24 software. ${ }^{1}$ Structure solution and refinement were performed by using SHELXTL-NT. ${ }^{2}$ Refinement of coordinates and anisotropic thermal parameters of non-hydrogen atoms were carried out by the full-matrix least-squares method. The hydrogen atoms attached to carbon atoms were generated with idealized geometries and isotropically refined using a riding model.

Crystallization: The compound $\mathbf{2 f}(5 \mathrm{mg})$ was dissolved in a $1 \mathrm{ml}$ mixture of $n$-hexane/DCM (2:1) and placed in a cabinet to evaporate slowly. After two days, $\mathbf{2} \mathbf{f}$ was obtained as white crystal.

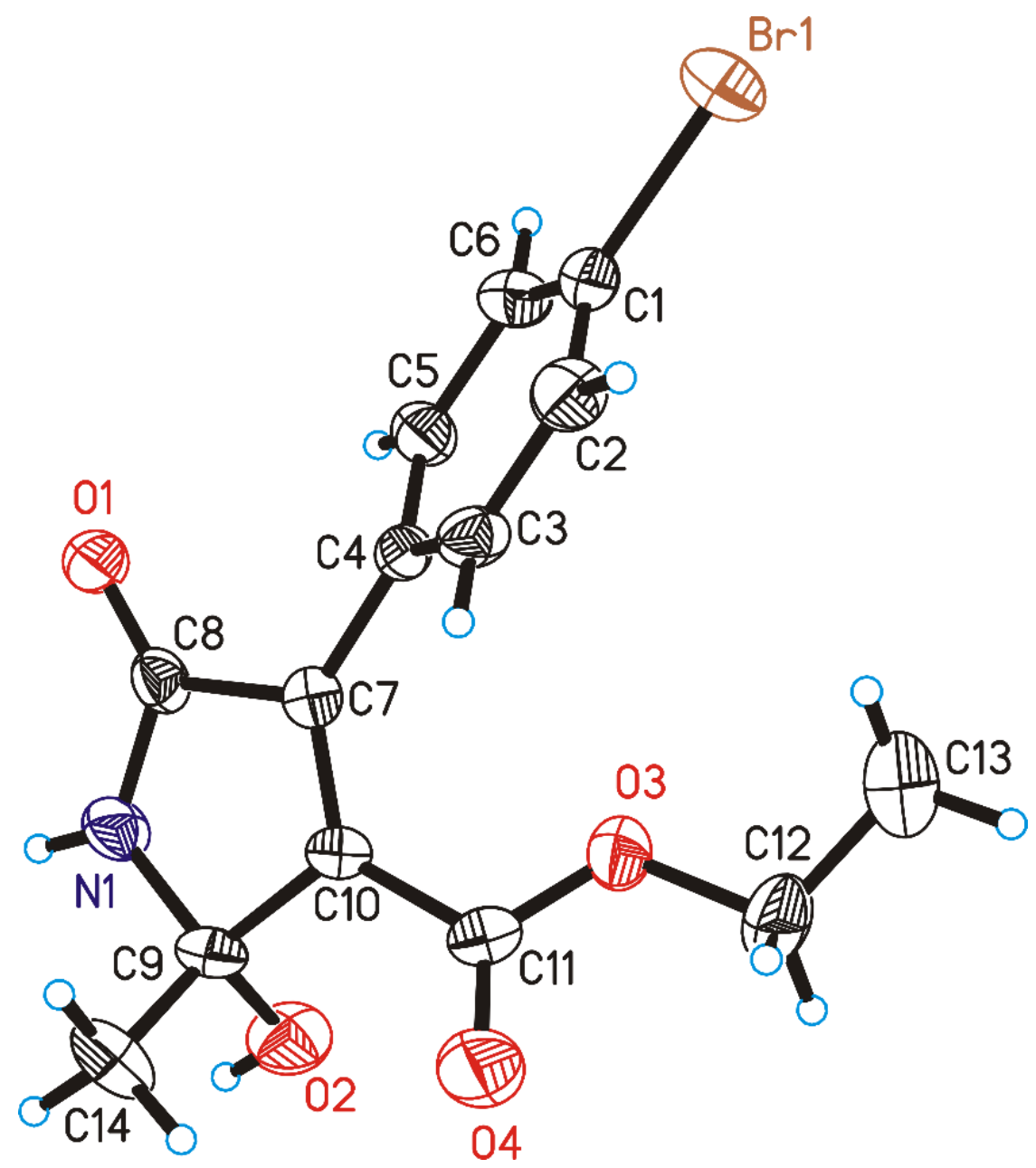

Figure S1. ORTEP diagram drawn with $30 \%$ ellipsoid probability for non-H atoms of the crystal structure of compound $\mathbf{2} \mathbf{f}$ determined at $293 \mathrm{~K}$. 
Table S1 Crystal data and structure refinement details for $\mathbf{2 f}$.

\begin{tabular}{c|c}
\hline Compound & $\mathbf{2 f}$ \\
\hline Empirical formula & $\mathrm{C}_{14} \mathrm{H}_{14} \mathrm{Br} \mathrm{N} \mathrm{O}_{4.5}$ \\
Formula weight & 348.17 \\
Crystal System & Monoclinic \\
Space group & $P 21 / \mathrm{n}$ \\
$a(\AA)$ & $9.838(4)$ \\
$b(\AA)$ & $15.861(6)$ \\
$c(\AA)$ & $20.361(9)$ \\
$\alpha\left(^{\circ}\right)$ & 90.00 \\
$\beta\left(^{\circ}\right)$ & $101.9810(10)$ \\
$V\left(^{\circ}\right)$ & 90.00 \\
$V\left(\AA^{3}\right)$ & $3108(2)$ \\
$Z$ & 8 \\
$D_{\mathrm{c}}\left(\mathrm{g} / \mathrm{cm}^{3}\right)$ & 1.488 \\
$F_{000}$ & 1408 \\
$\mu\left(\mathrm{mm}^{-1}\right)$ & 2.660 \\
$\theta_{\text {max }}\left(^{\circ}\right)$ & 25.36 \\
Total reflections & 19146 \\
Unique reflections & 5580 \\
Reflections $[I>2 \sigma(I)]$ & 2173 \\
Parameters & 376 \\
$R_{\text {int }}$ & 0.1136 \\
Goodness-of-fit & 1.007 \\
$R\left[F^{2}>2 \sigma\left(F^{2}\right)\right]$ & 0.0731 \\
$w R\left(F^{2}\right.$, all data) & 0.1412 \\
CCDC No. & 2006864 \\
\hline
\end{tabular}

\section{X-Ray Data Collection and Structure Refinement Details for compound 4e:}

A good quality single crystal of size $0.43 \times 0.23 \times 0.19 \mathrm{~mm}$, was selected under a polarizing microscope and was mounted on a glass fiber for data collection. Single crystal Xray data for compound $\mathbf{4 e}$ were collected on the Rigaku Kappa 3 circle diffractometer equipped with the AFC12 goniometer and enhanced sensitivity (HG) Saturn724+CCD detector in the $4 \times 4$ bin mode using the monochromated Mo-K $\alpha$ radiation generated from the microfocus sealed tube MicroMax-003 X-ray generator equipped with specially designed confocal multilayer optics. Data collection was performed using $\omega$-scans of $0.5^{\circ}$ steps at 293(2) K. Cell determination, data collection and data reduction was performed using the Rigaku CrystalClear-SM Expert 2.1 b24 software. ${ }^{1}$ Structure solution and refinement were performed by using SHELXTL-NT. ${ }^{2}$ Refinement of coordinates and anisotropic thermal parameters of non-hydrogen atoms were carried out by the full-matrix least-squares method. The hydrogen atoms attached to carbon atoms were generated with idealized geometries and isotropically refined using a riding model.

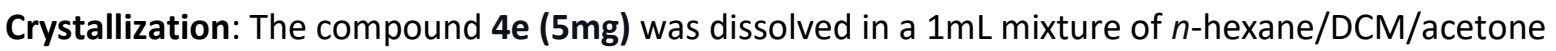
(2:1:1) and placed in a cabinet to evaporate slowly. After two days, $4 \mathbf{e}$ was obtained as white crystal. 


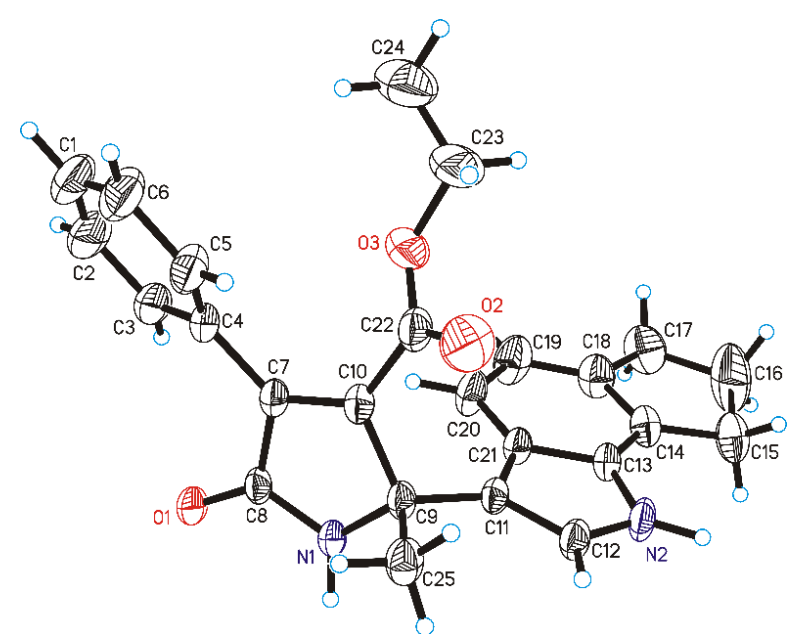

Figure S2. ORTEP diagram drawn with $30 \%$ ellipsoid probability for non-H atoms of the crystal structure of compound $4 \mathrm{e}$ determined at $293 \mathrm{~K}$.

Table S2 Crystal data and structure refinement details for $\mathbf{4 e .}$

\begin{tabular}{c|c}
\hline Compound & 4 e \\
\hline Empirical formula & $\mathrm{C}_{25} \mathrm{H}_{24} \mathrm{~N}_{2} \mathrm{O}_{3}$ \\
Formula weight & 400.46 \\
Crystal System & Triclinic \\
Space group & $P-1$ \\
$a(\AA)$ & $9.3094(3)$ \\
$b(\AA)$ & $9.4648(3)$ \\
$c(\AA)$ & $13.4239(4)$ \\
$\alpha\left(^{\circ}\right)$ & $70.898(3)$ \\
$\beta\left({ }^{\circ}\right)$ & $76.491(3)$ \\
$V\left(^{\circ}\right)$ & $77.185(3$ \\
$V\left(\AA^{3}\right)$ & $1073.07(6)$ \\
$Z$ & 2 \\
$D_{c}\left(g / \mathrm{cm}^{3}\right)$ & 1.239 \\
$F_{000}$ & 424 \\
$\mu\left(\mathrm{mm}^{-1}\right)$ & 0.656 \\
$\theta_{\text {max }}\left({ }^{\circ}\right)$ & 72.80 \\
Total reflections & 21777 \\
Unique reflections & 4045 \\
Reflections $[I>2 \sigma(I)]$ & 3638 \\
Parameters & 282 \\
$R_{\text {int }}$ & 0.1291 \\
Goodness-of-fit & 1.084 \\
$R\left[F^{2}>2 \sigma\left(F^{2}\right)\right]$ & 0.0756 \\
$w R\left(F^{2}\right.$, all data $)$ & 0.2164 \\
$C C D C$ No. & 2009054 \\
\hline &
\end{tabular}

1. CrystalClear 2.1, Rigaku Corporation, Tokyo, Japan

2. Sheldrick, G. M. Acta Crystallogr., Sect. A 2008, 64, 112-122. 


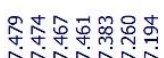

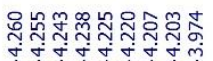

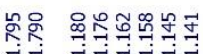

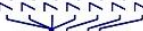

每

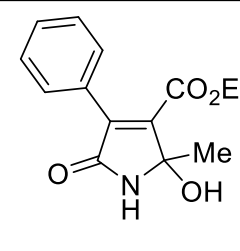

$2 a$

$400 \mathrm{MHz}^{2} \mathrm{CDCl}_{3}$

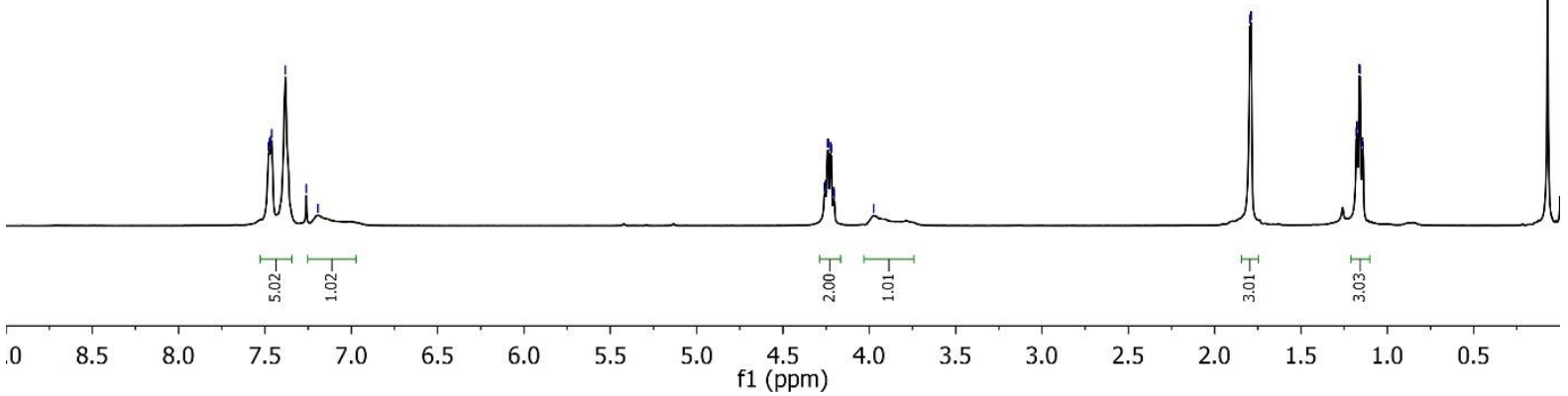

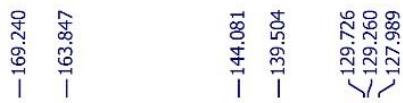

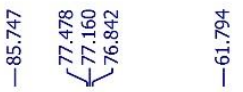

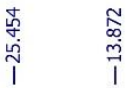

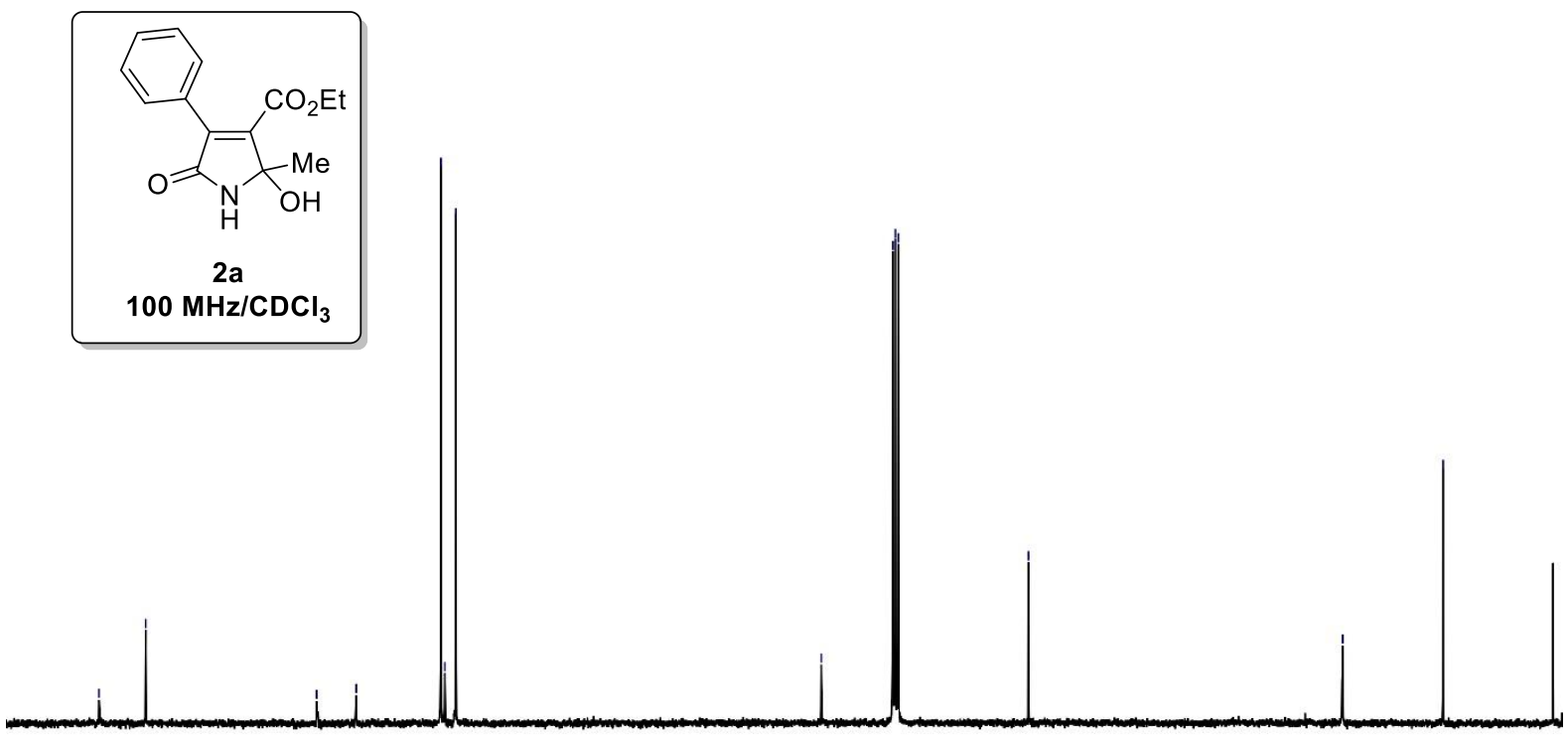



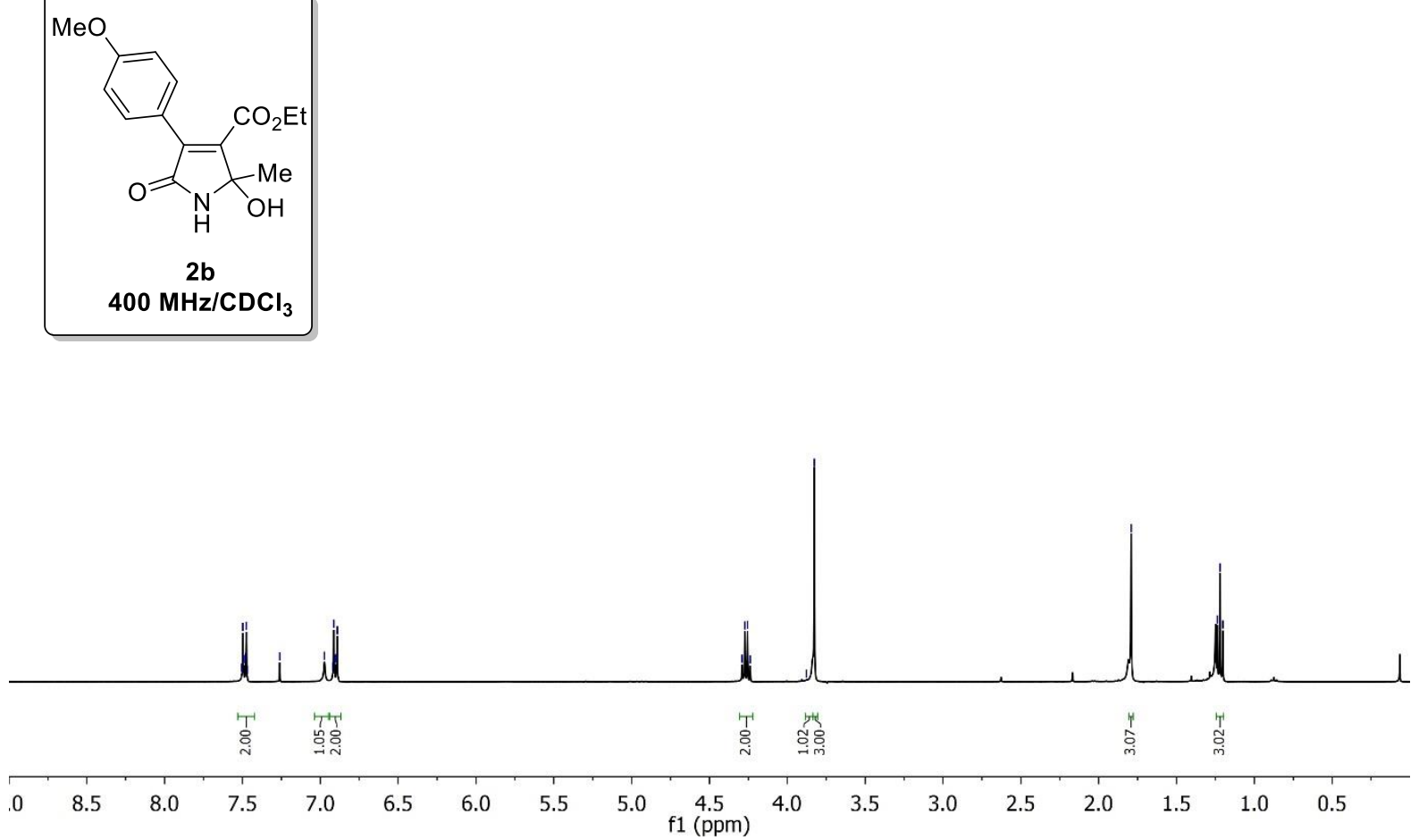

喅
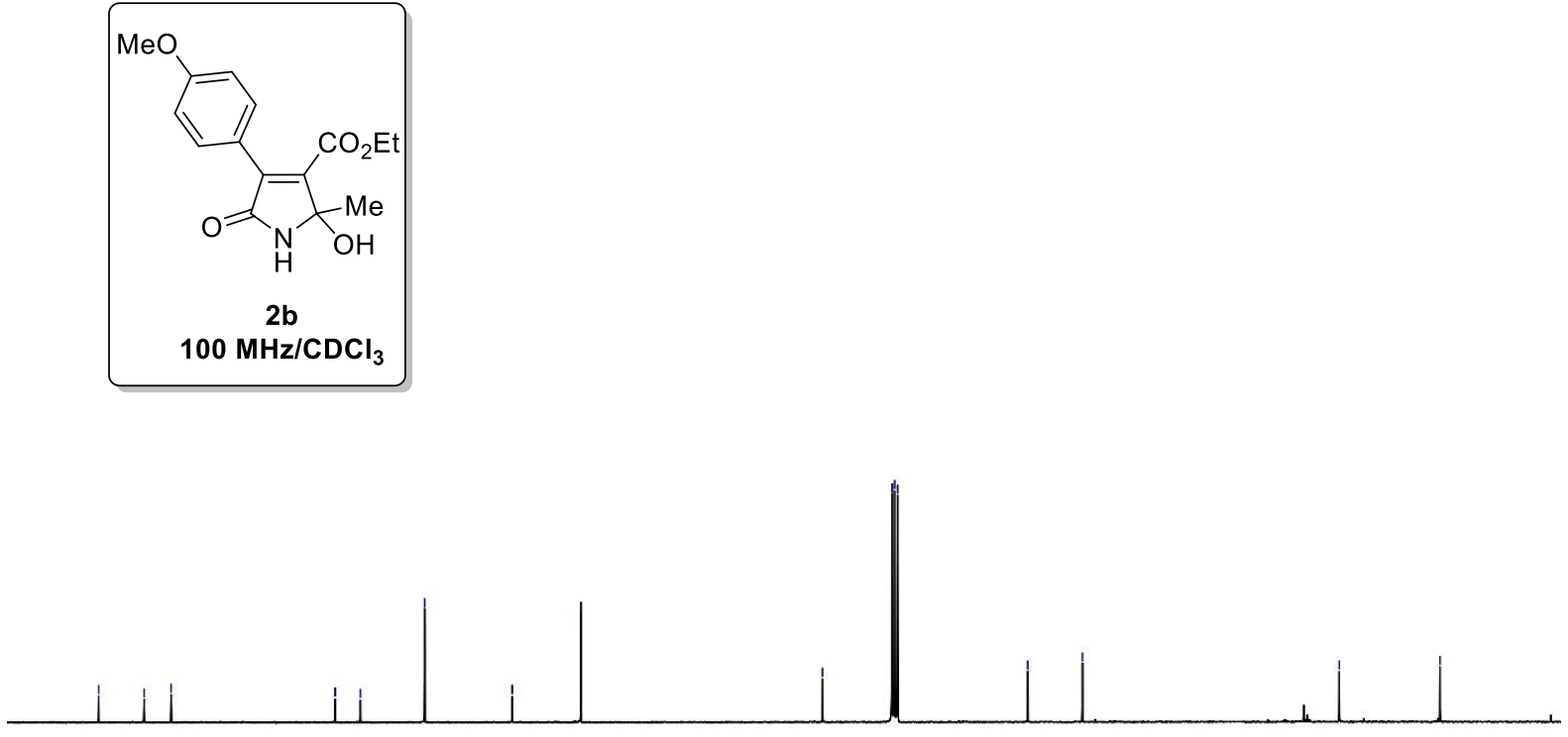

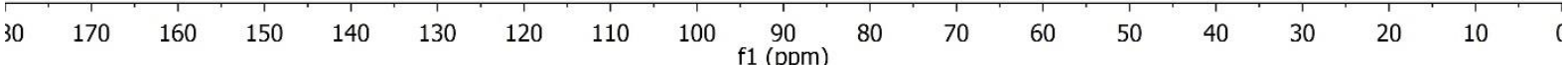




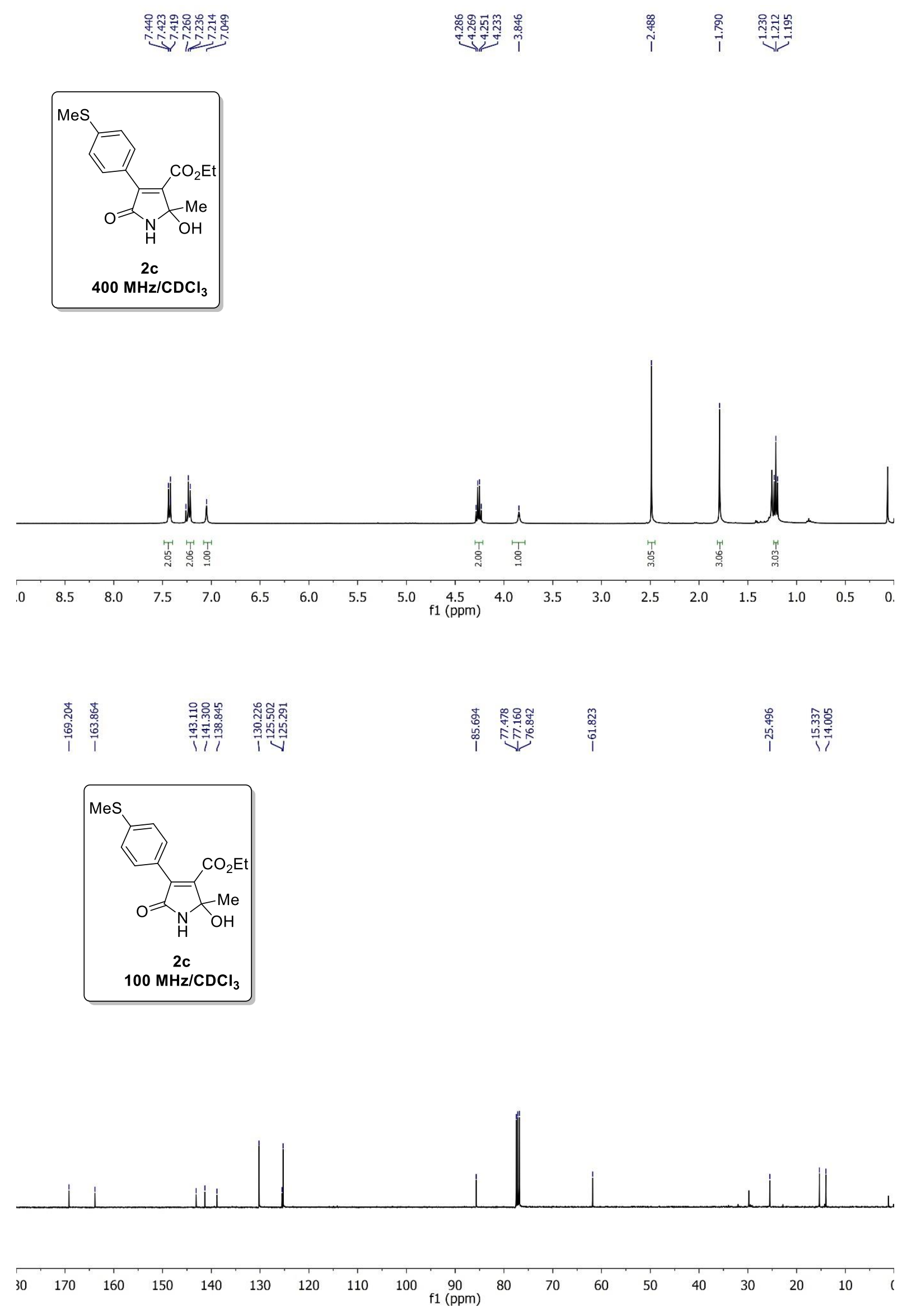



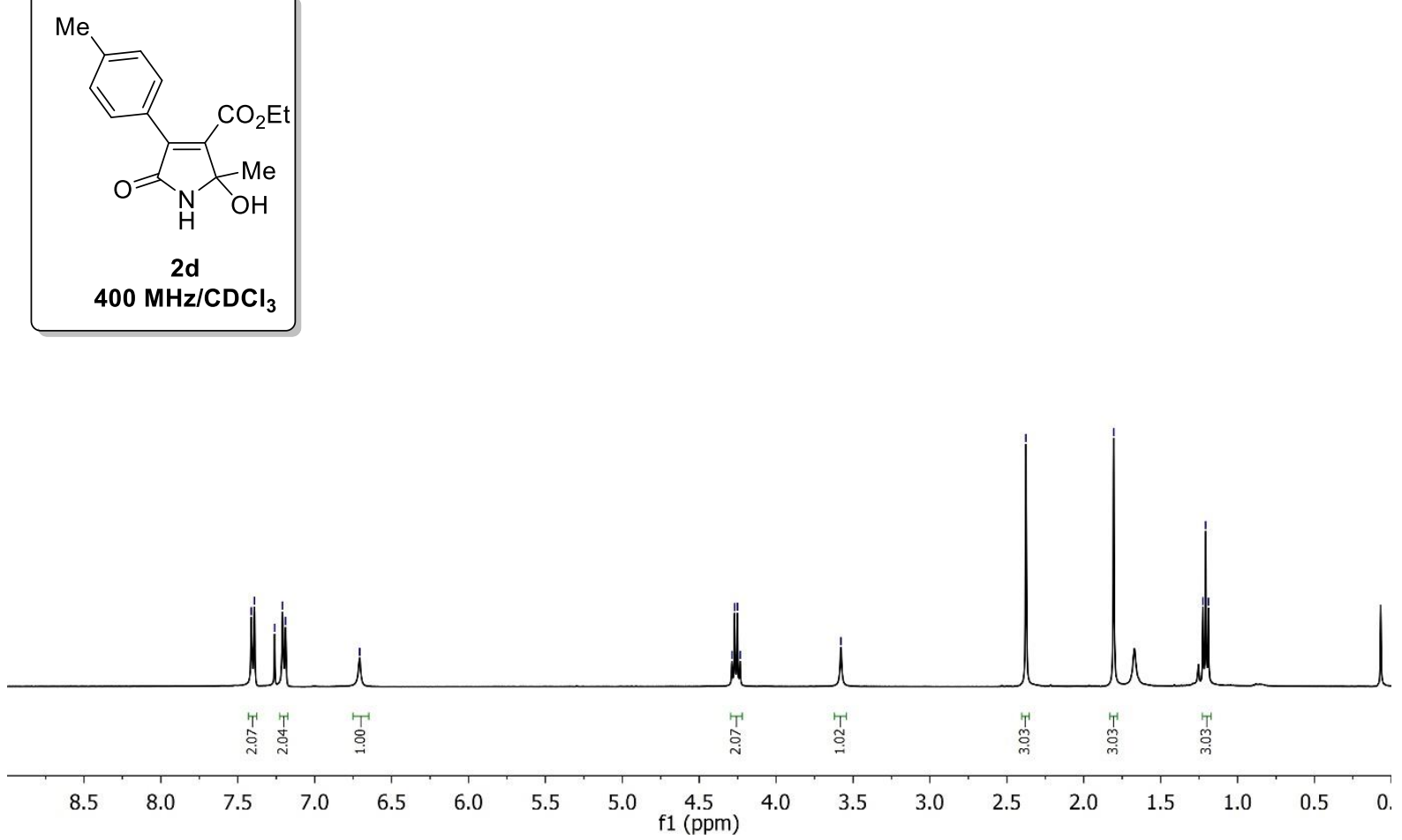

in

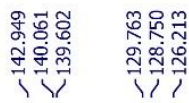

$\mathrm{Me}$

$\Longrightarrow$

$\mathrm{CO}_{2} \mathrm{Et}$

$=\underset{\mathrm{N}}{-\mathrm{Me}}$

$2 d$

$100 \mathrm{MHz} / \mathrm{CDCl}_{3}$

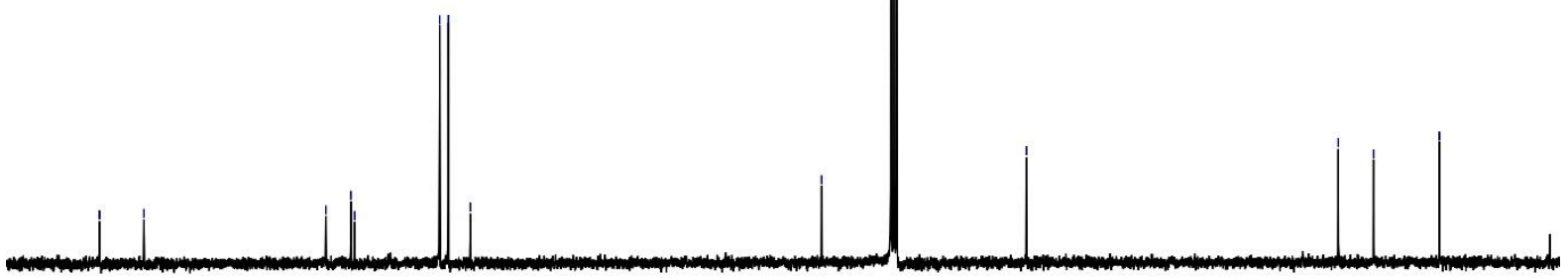

$30 \quad 170$

$160 \quad 150 \quad 140$

$130-120$ 

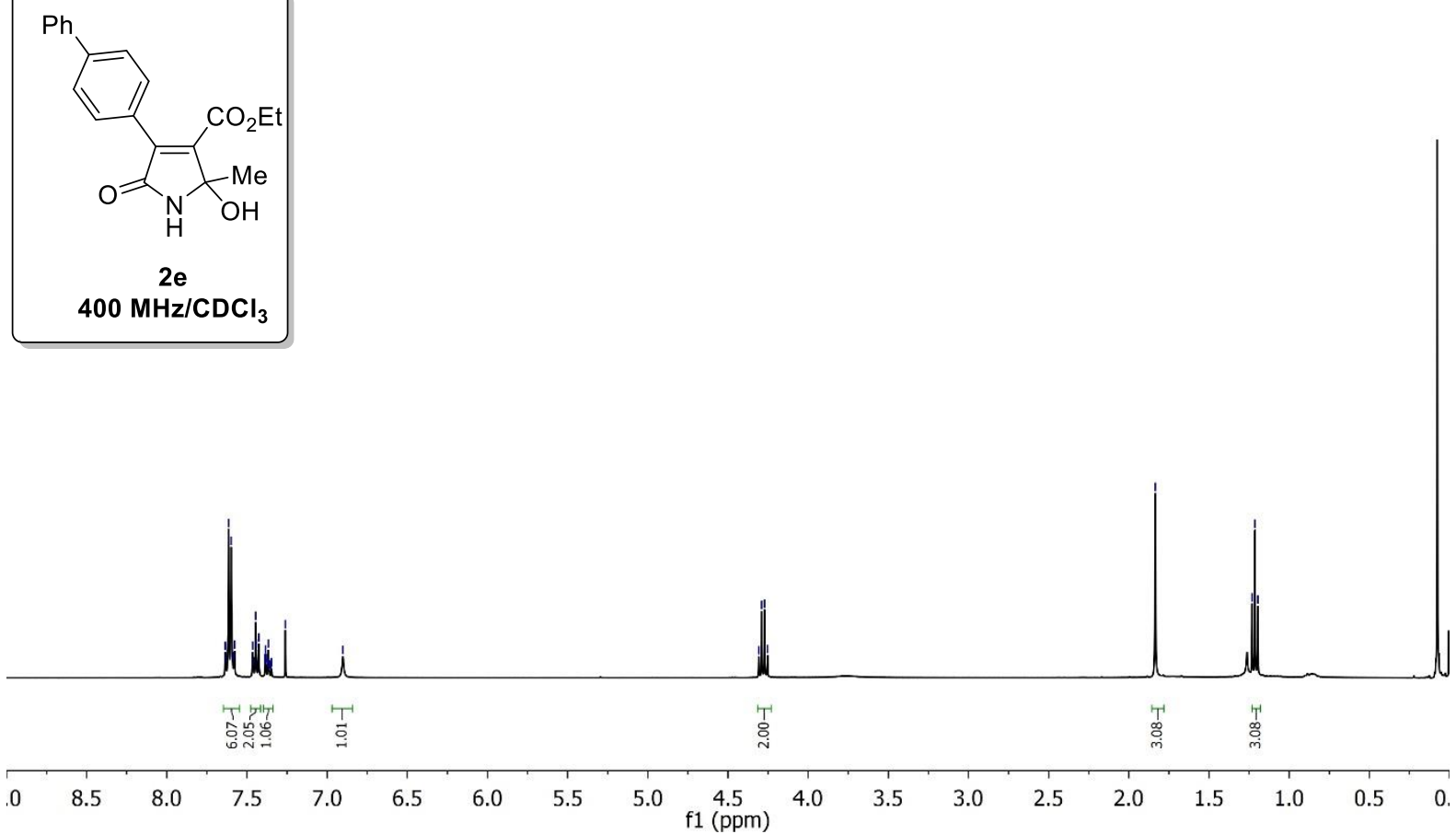

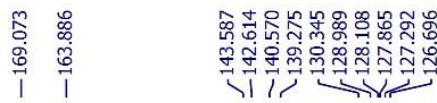

1 诲

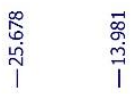

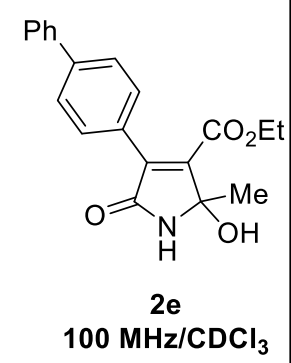

$100 \mathrm{MHz} \mathrm{CDCl}_{3}$

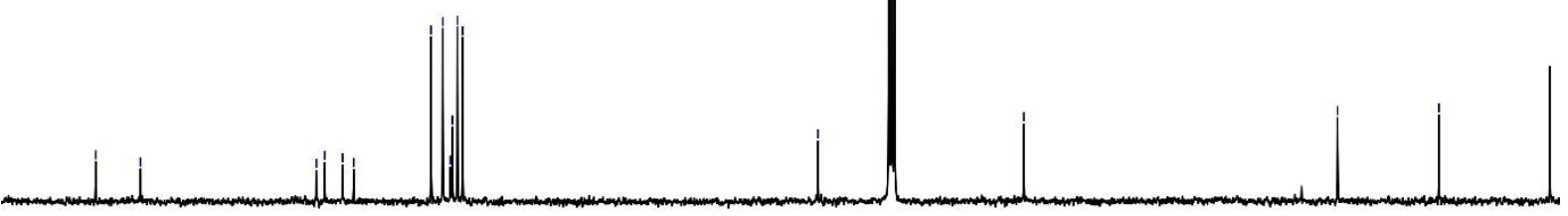

$30 \quad 170$

140

$130 \quad 120$

$100 \underset{\mathrm{f} 1(\mathrm{ppm})}{90} 80$ 


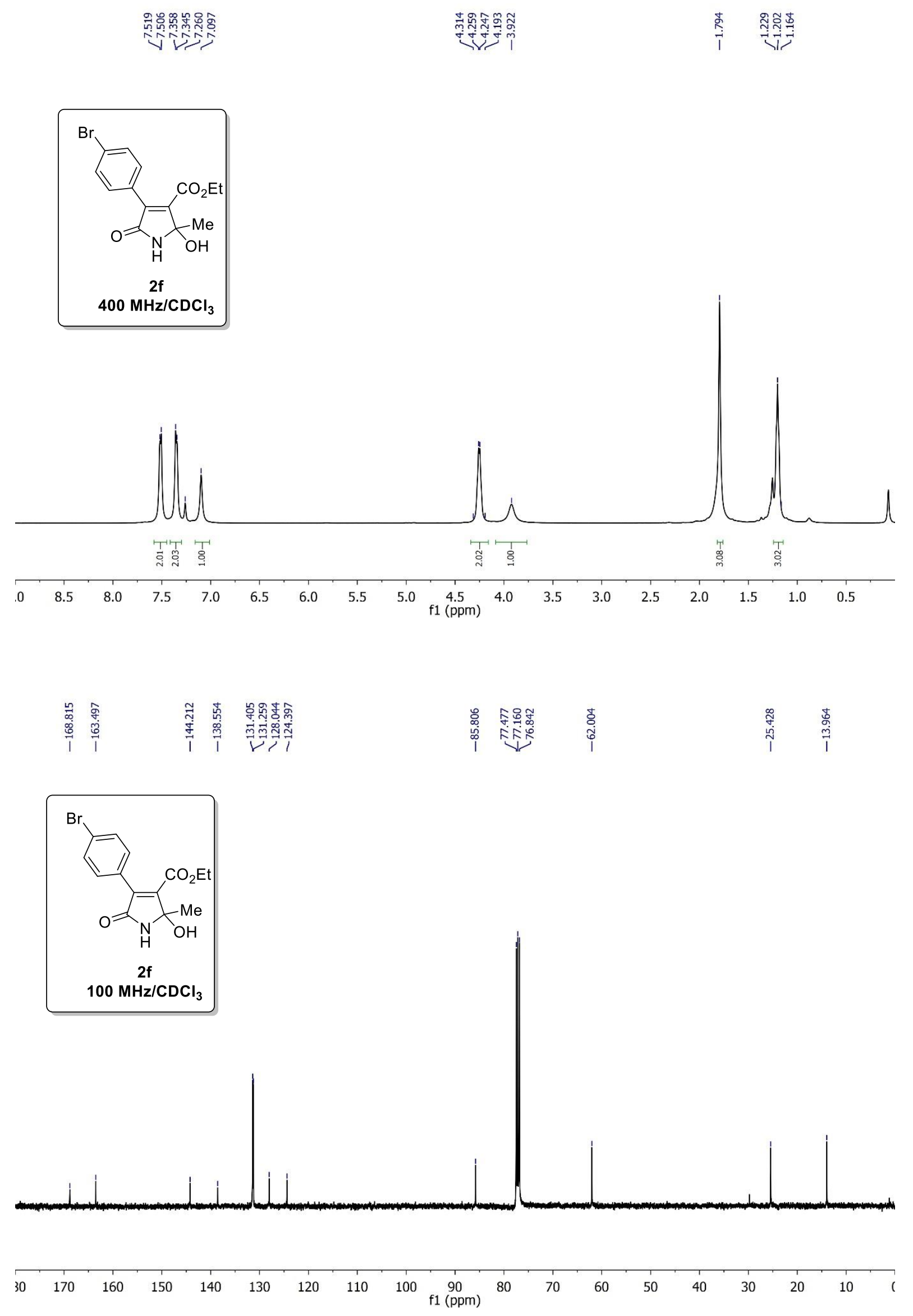




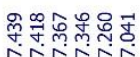

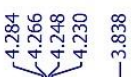

草

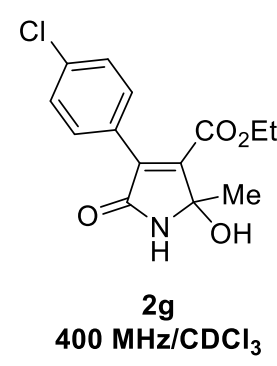

$400 \mathrm{MHz} / \mathrm{CDCl}_{3}$

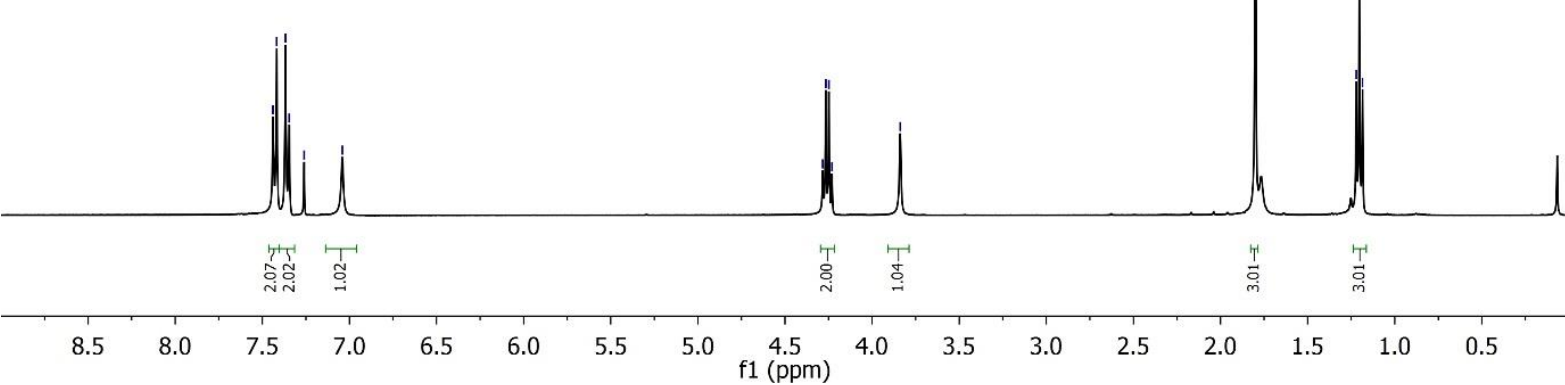

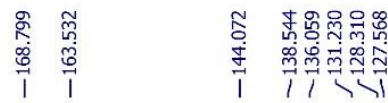

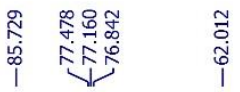

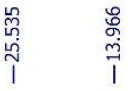
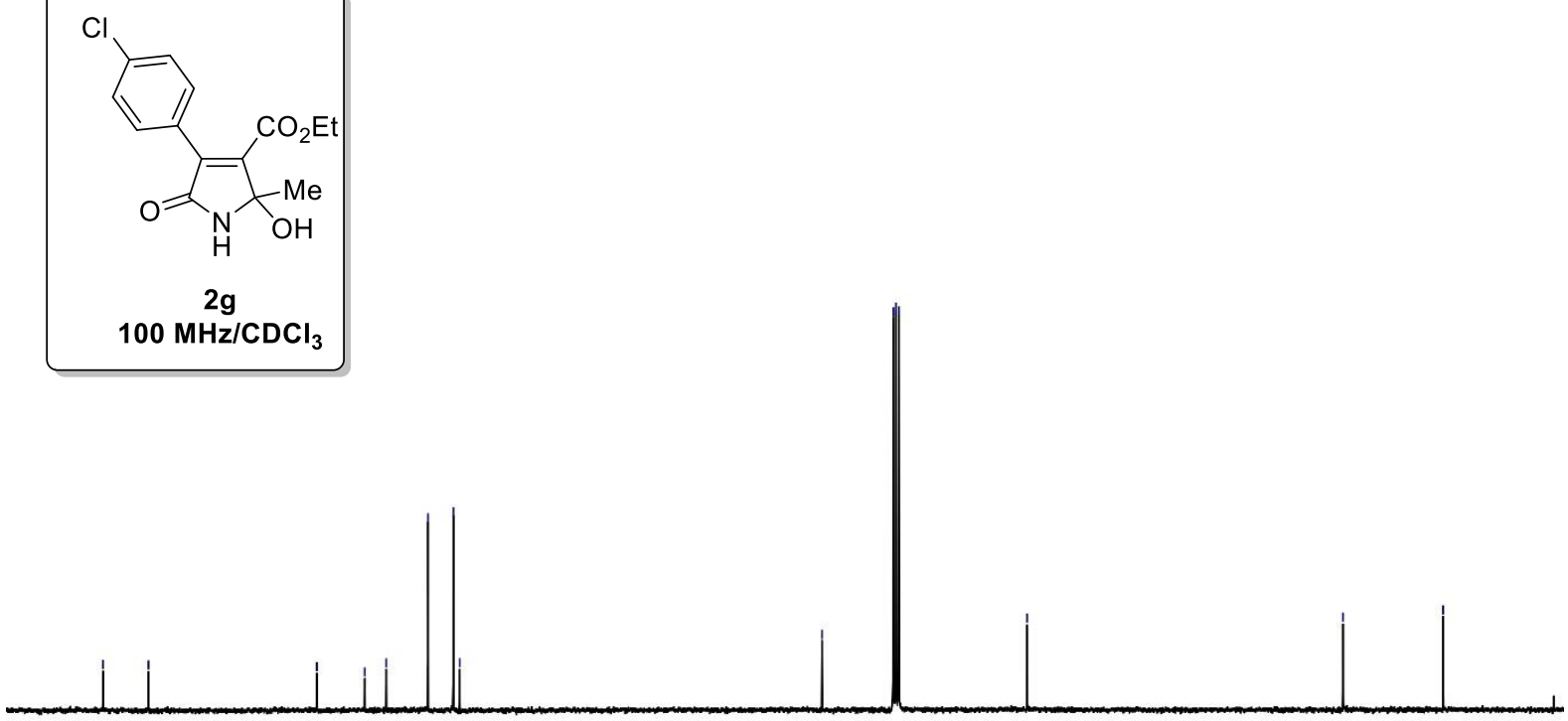

$30 \quad 170$

140

$130 \quad 120$

$100 \underset{\mathrm{f} 1(\mathrm{ppm})}{90} 80$

$\begin{array}{lllllll}70 & 60 & 50 & 40 & 30 & 20 & 10\end{array}$ 


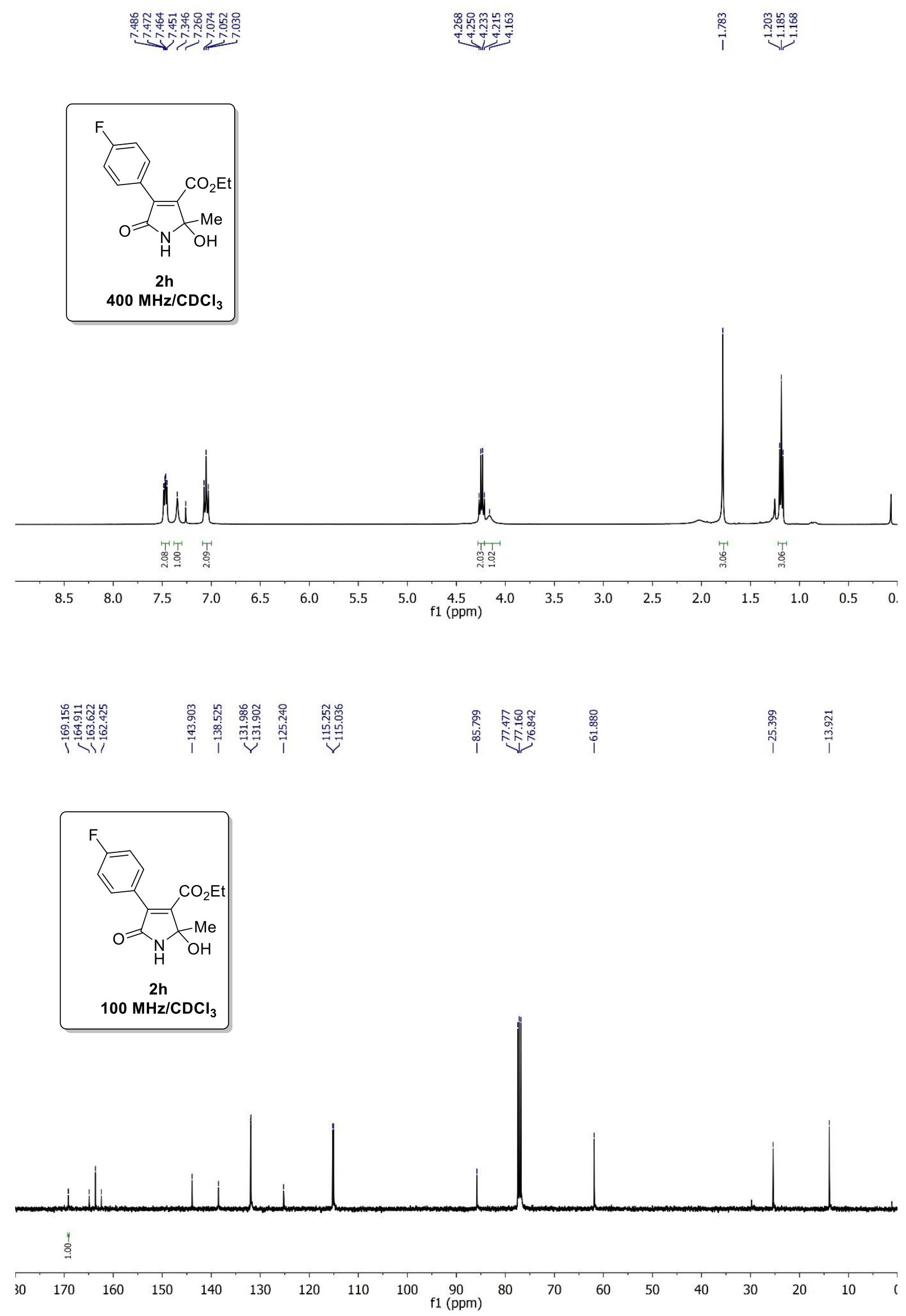




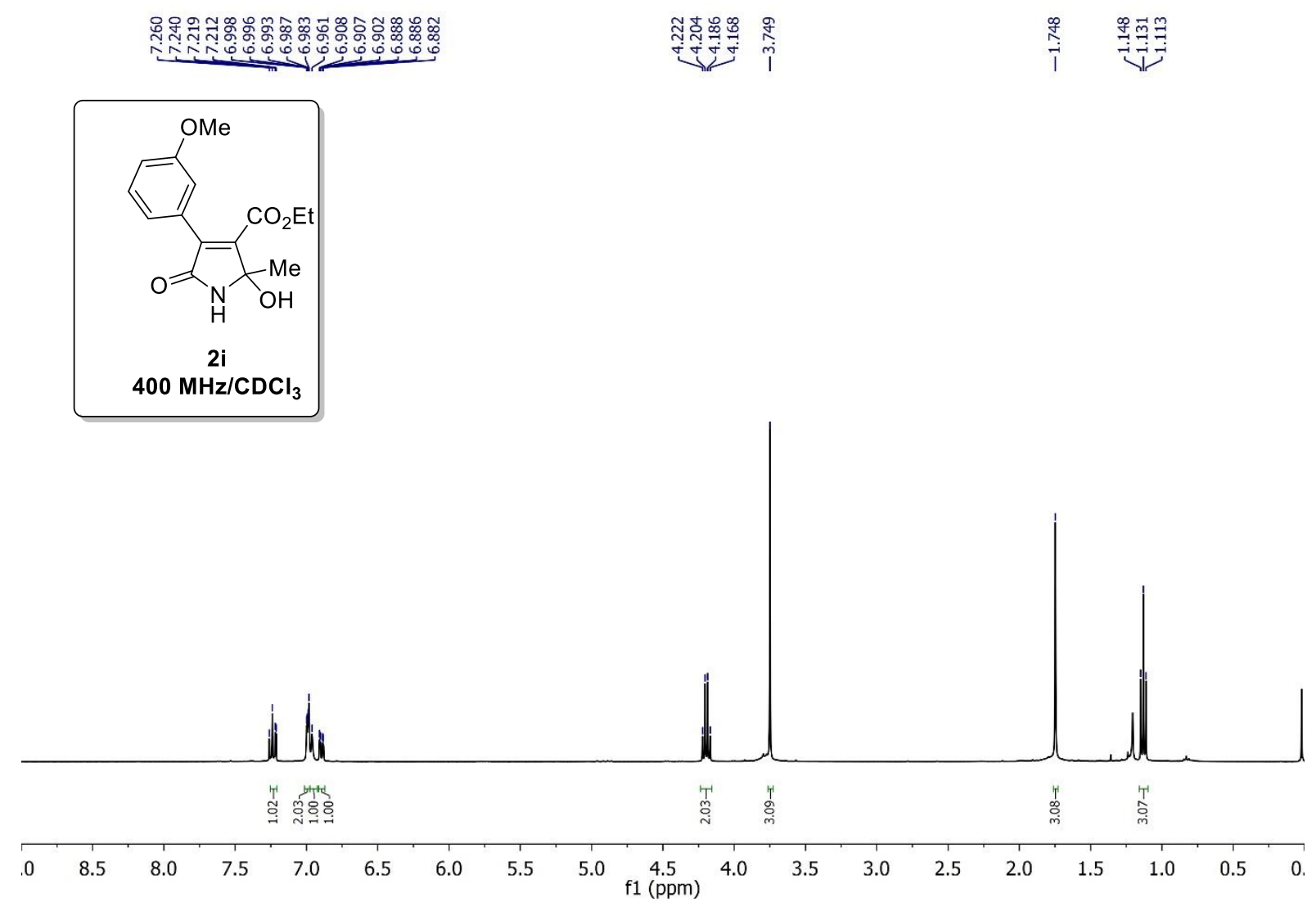

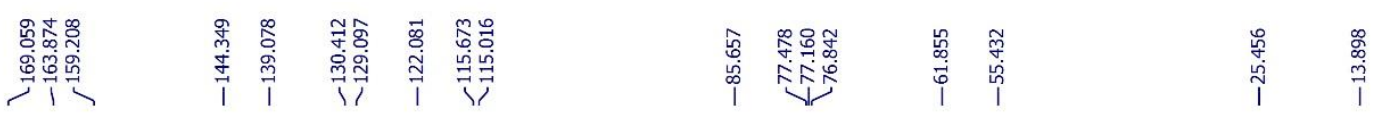
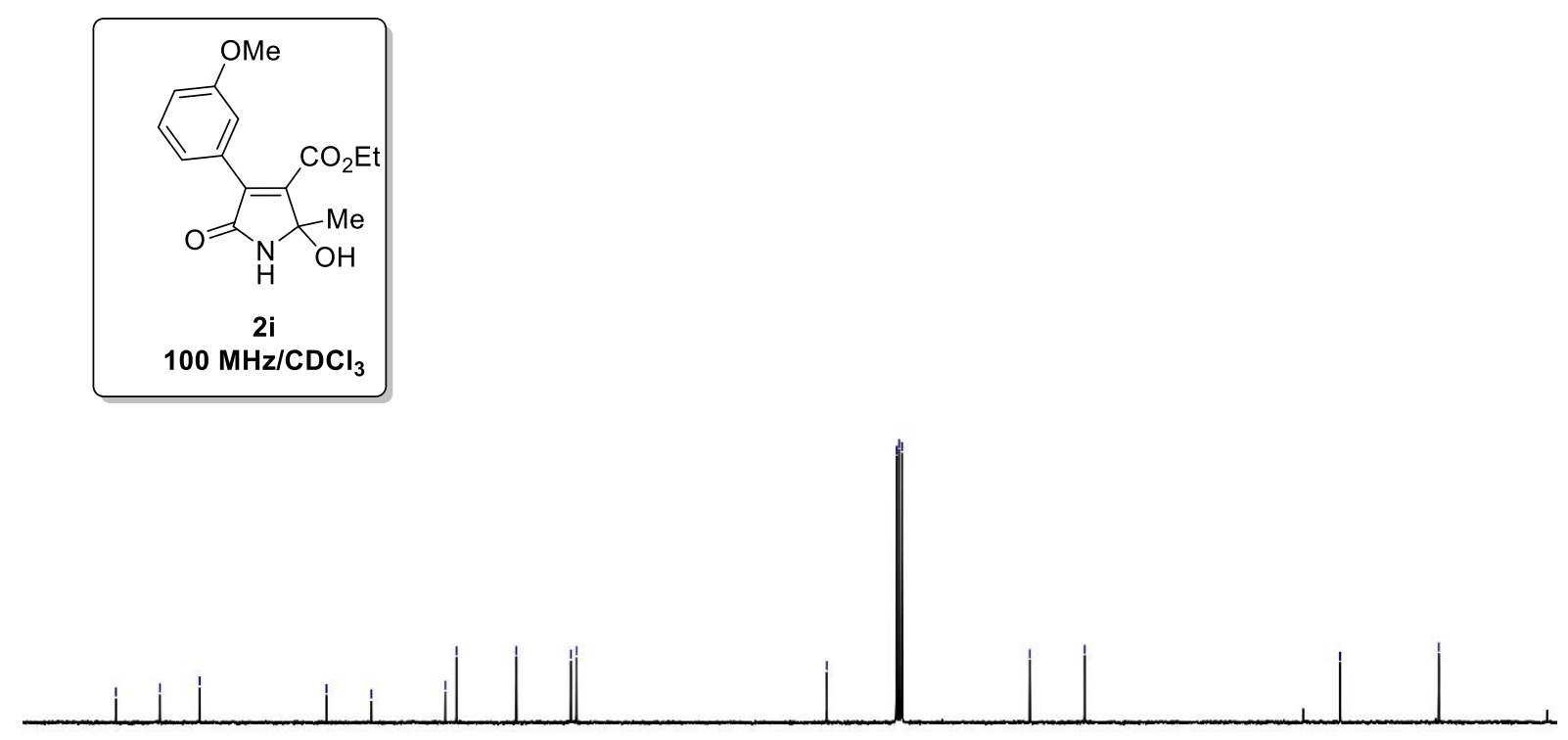

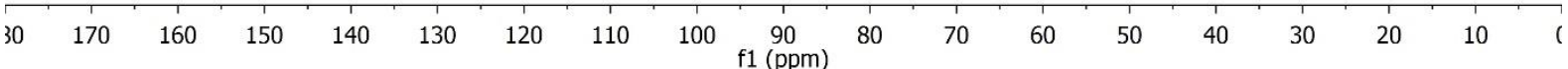




$$
\text { 400 } \mathrm{MHz}_{\mathbf{C} \mathrm{CDCl}_{3}}^{\mathrm{Bj}}
$$
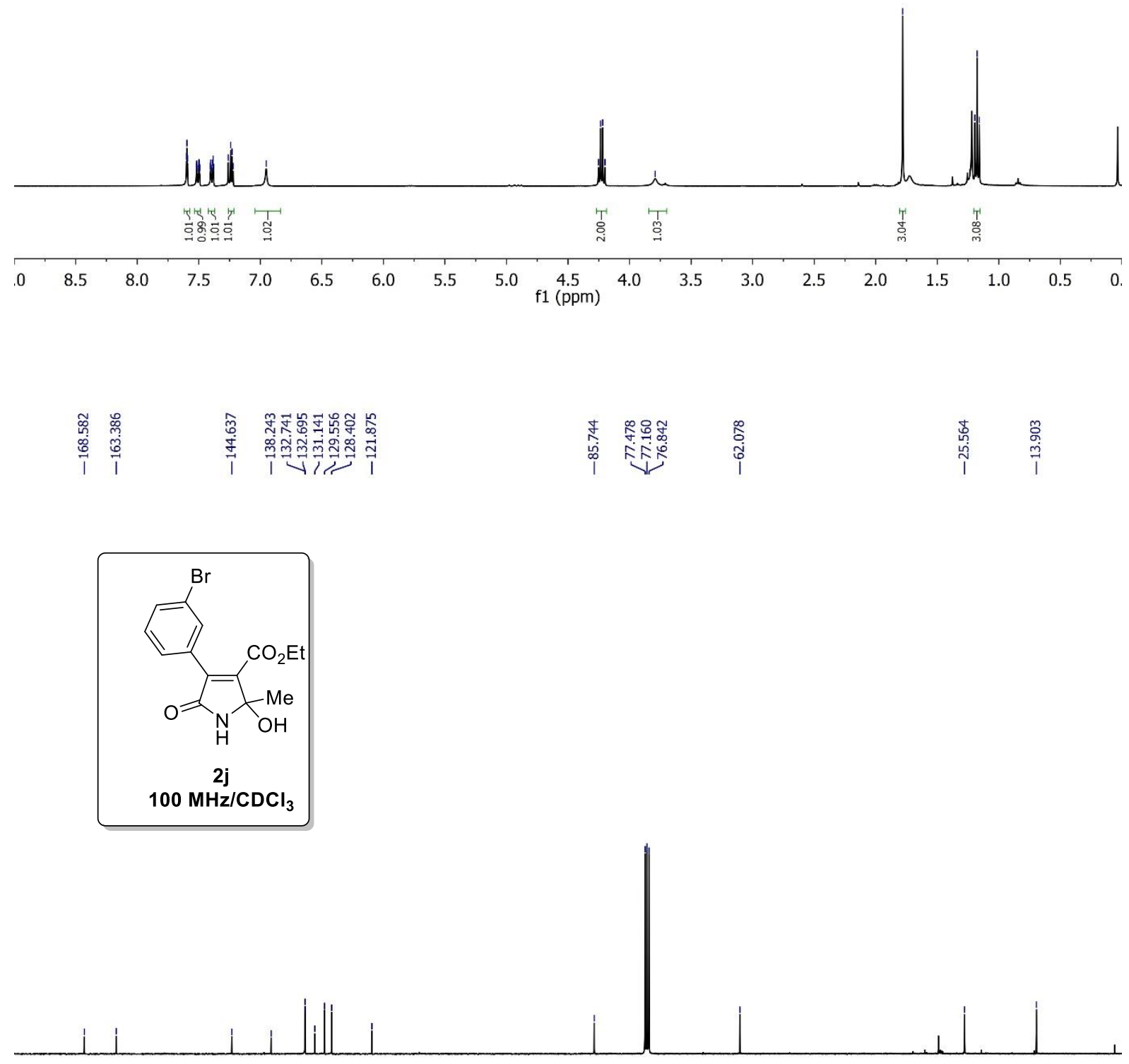

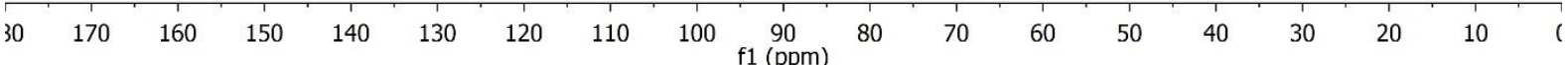




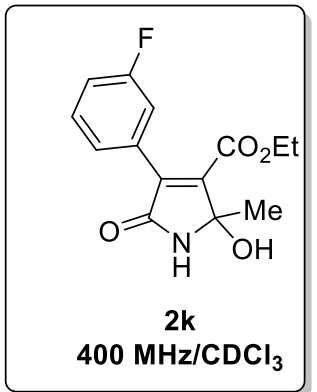

$400 \mathrm{MHz} / \mathrm{CDCl}_{3}$

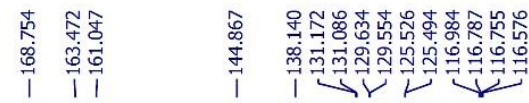
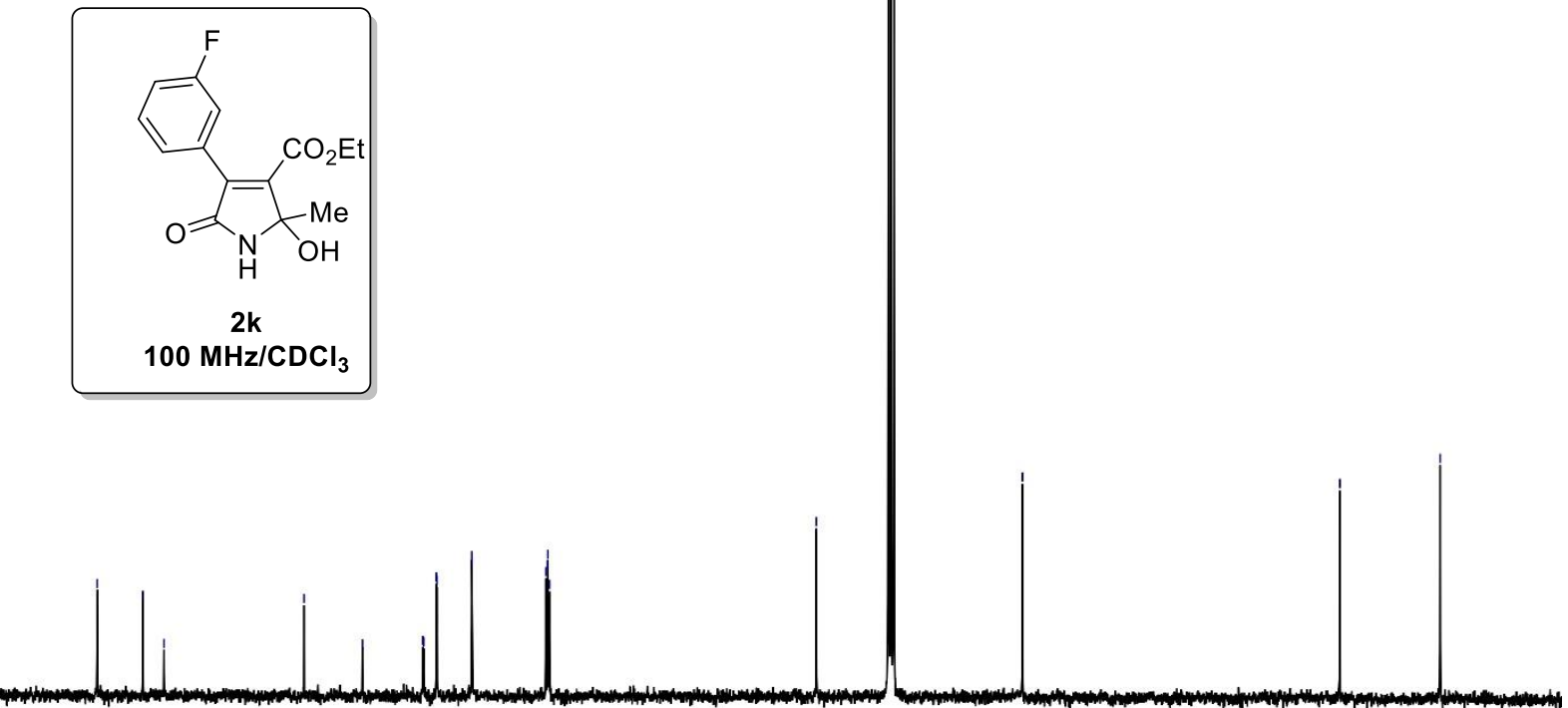

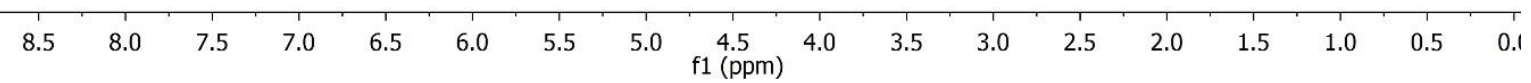




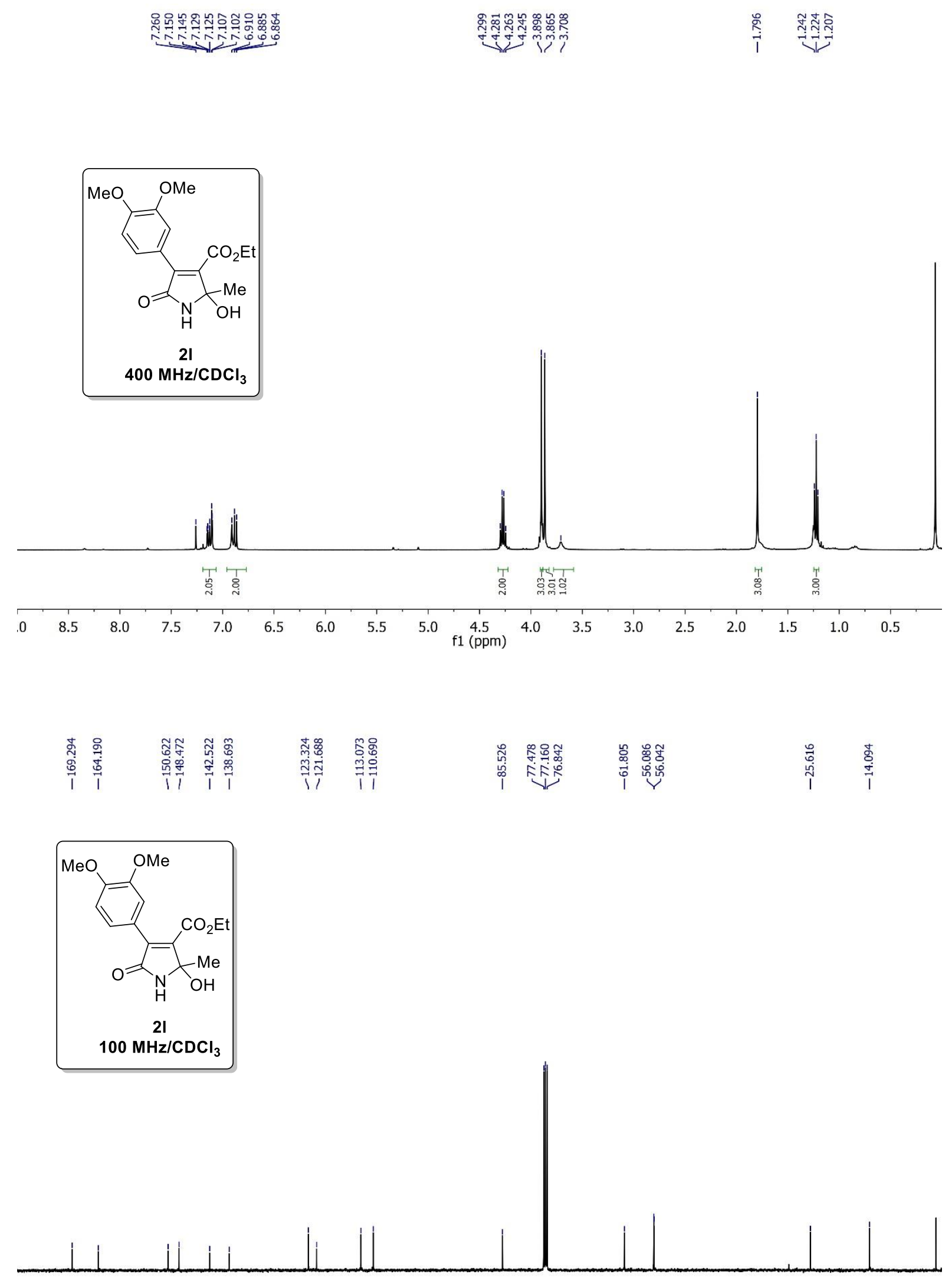

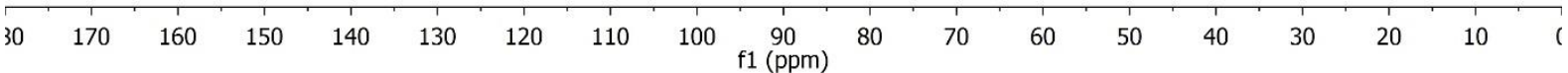




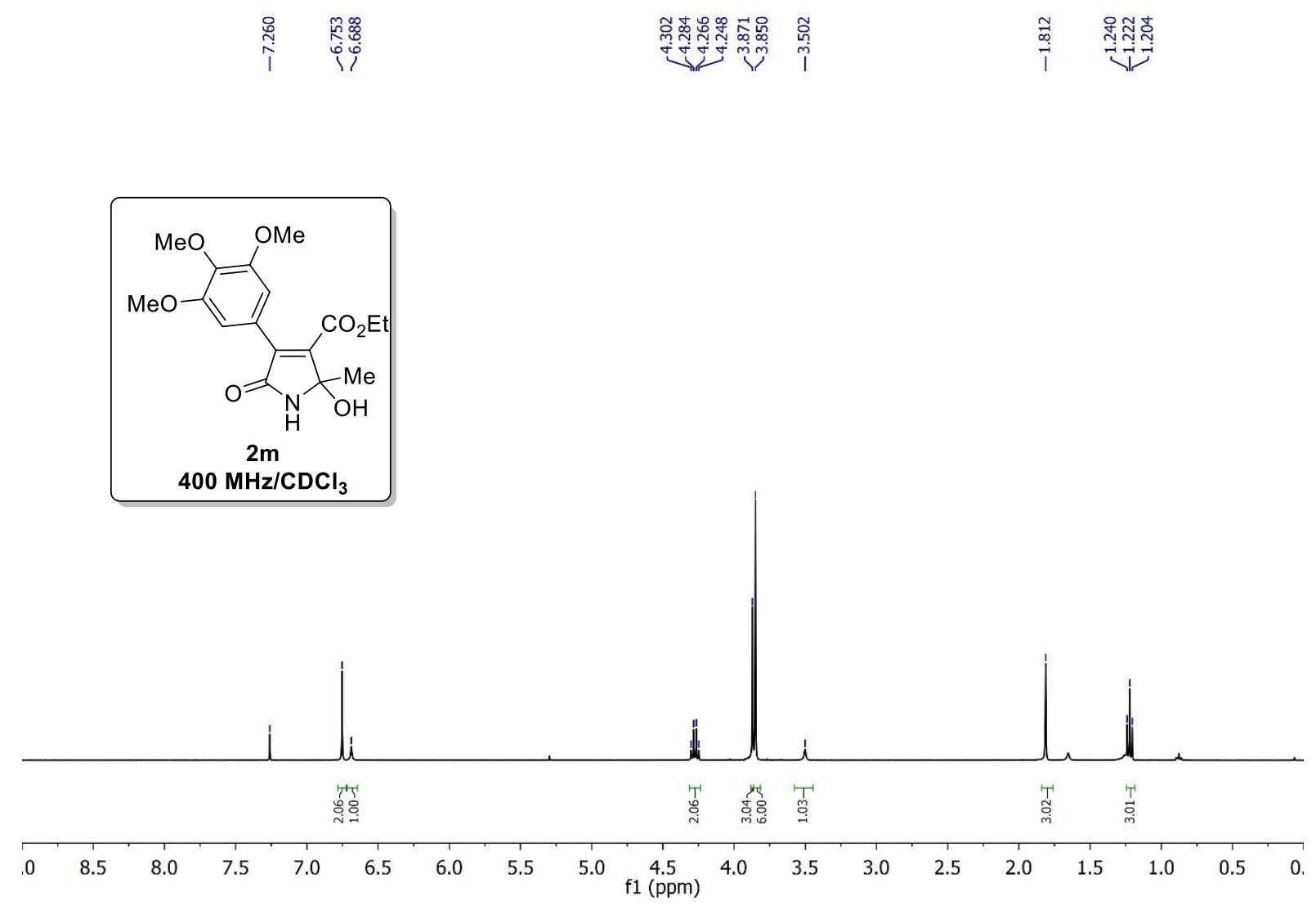

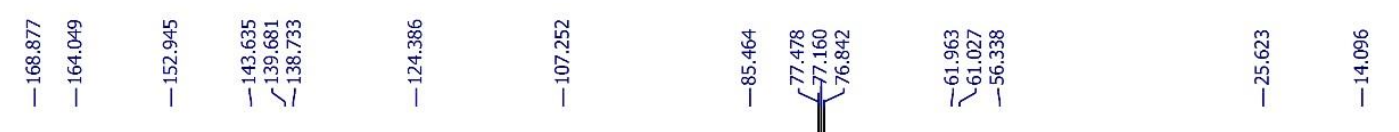

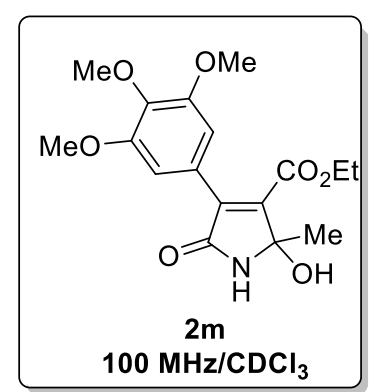

180

\begin{tabular}{|c|c|c|c|c|c|c|c|c|c|c|c|c|c|c|c|c|}
\hline 170 & 160 & 150 & 140 & 130 & 120 & 110 & 100 & $\begin{array}{c}90 \\
(\mathrm{ppm})\end{array}$ & 80 & 70 & 60 & 50 & 40 & 30 & 20 & 10 \\
\hline
\end{tabular}




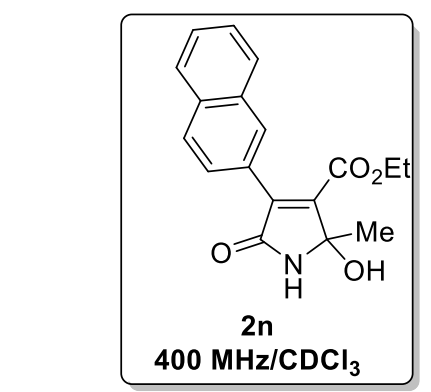

$400 \mathrm{MHz} / \mathrm{CDCl}_{3}$

崩

廿

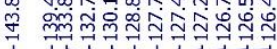

1 N

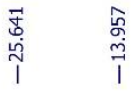

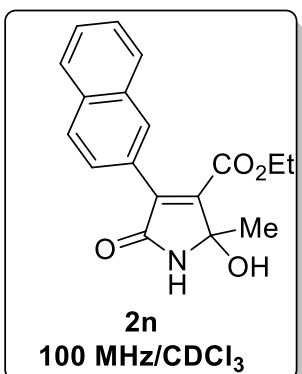

$100 \mathrm{MHz}^{-\mathrm{CDCl}_{3}}$

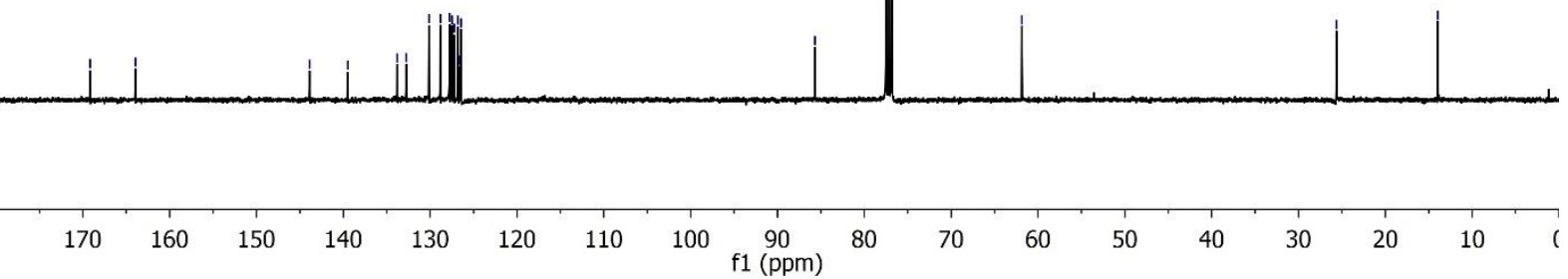




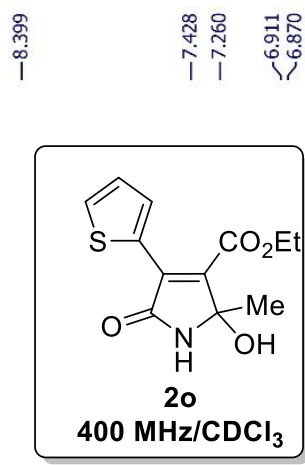

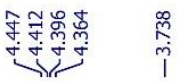

定

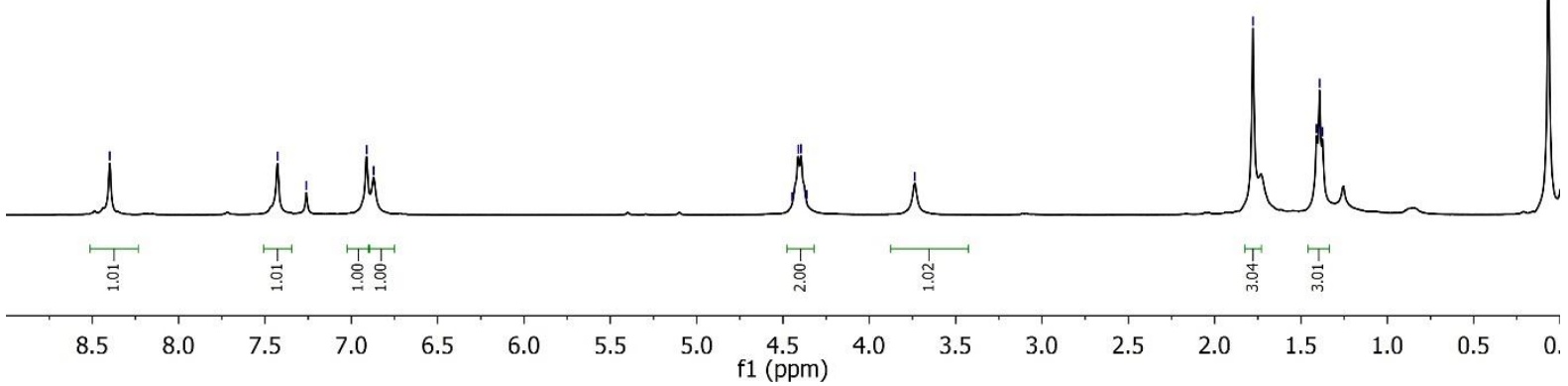

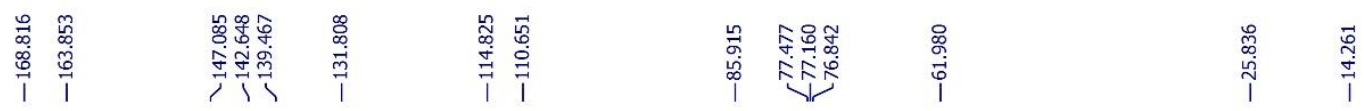

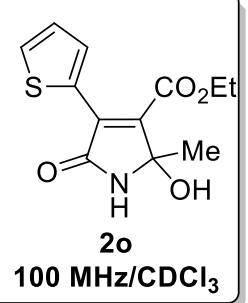

180

$170 \quad 160$

150

$140 \quad 130$

$120 \quad 110$

$100 \underset{\mathrm{f} 1(\mathrm{ppm})}{90}$

\begin{tabular}{ll}
$70 \quad 60$ \\
\hline
\end{tabular}

50

(30

$20 \quad 10$ 


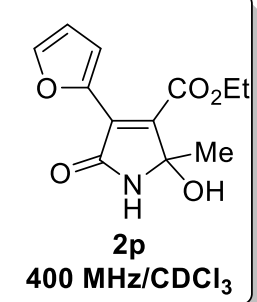

$400 \mathrm{MHz} \mathrm{CDCl}_{3}$

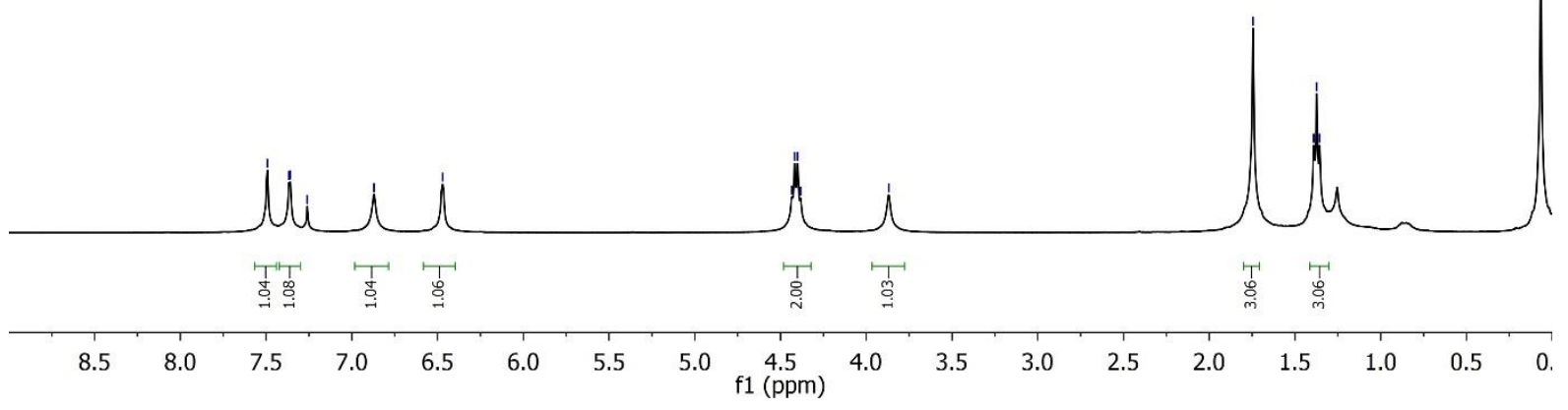

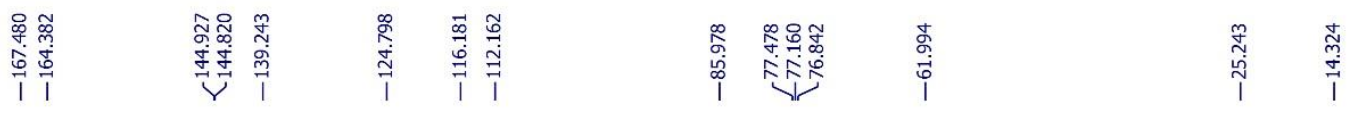

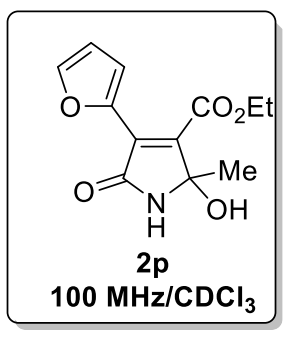

180

$170 \quad 160$

150

$140 \quad 130$

$120 \quad 110$

$100 \begin{gathered}90 \\ \mathrm{f} 1(\mathrm{ppm})\end{gathered}$

60

50

$30 \quad 20 \quad 10$ 

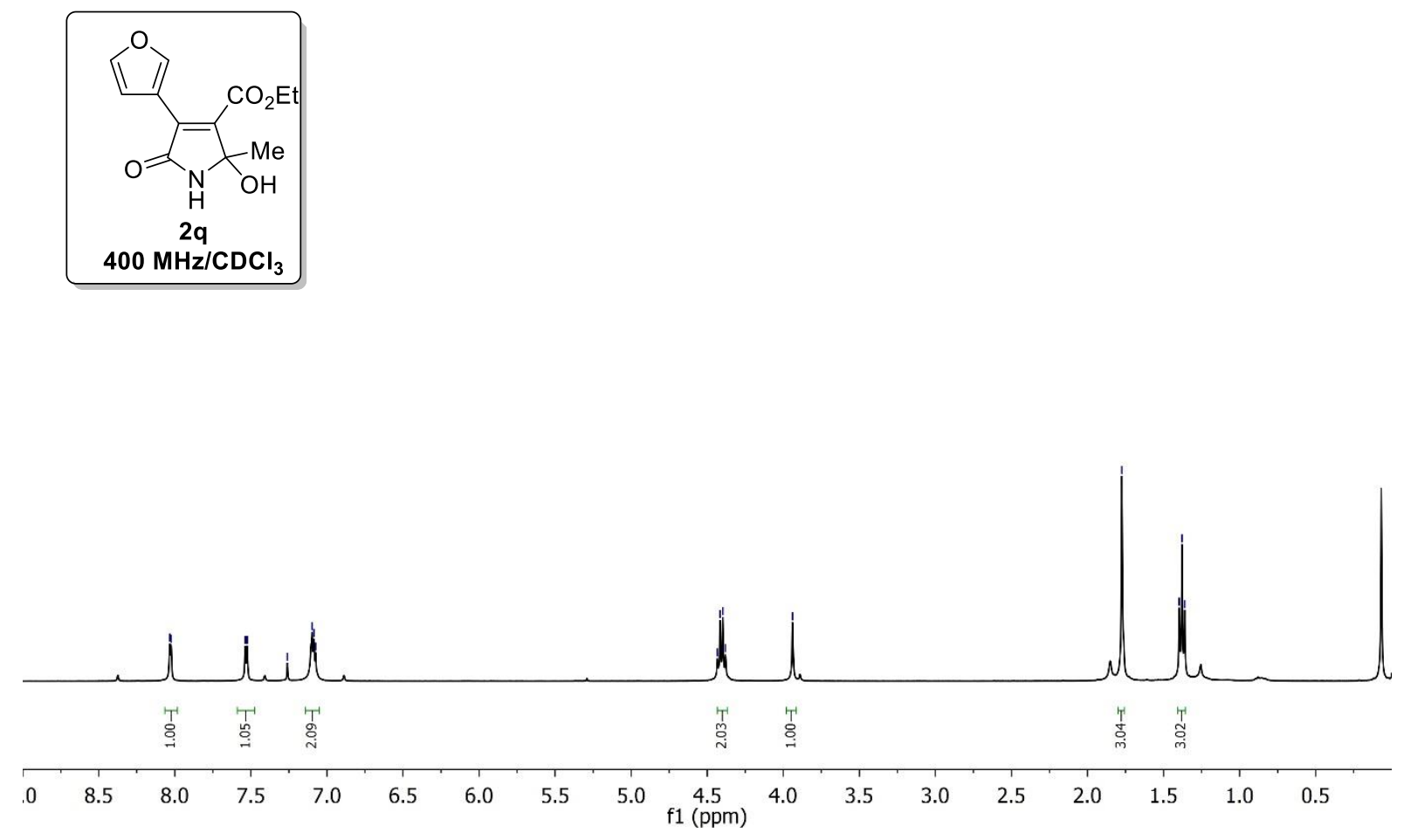

\begin{tabular}{|c|c|c|c|c|}
\hline 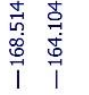 & 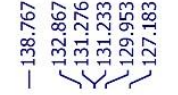 & 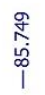 & 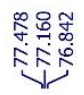 & \\
\hline
\end{tabular}<smiles>CC(=O)C1=C(c2ccco2)C(=O)NC1(C)O</smiles>

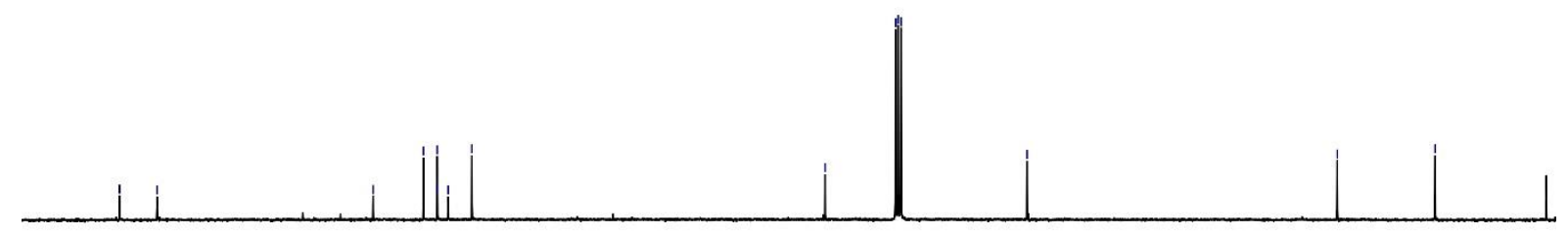

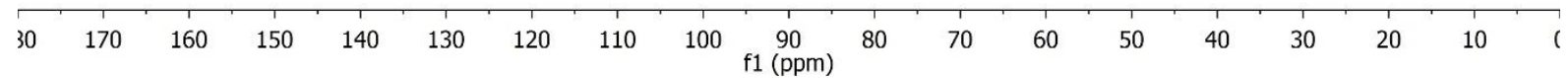




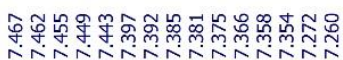

员

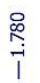
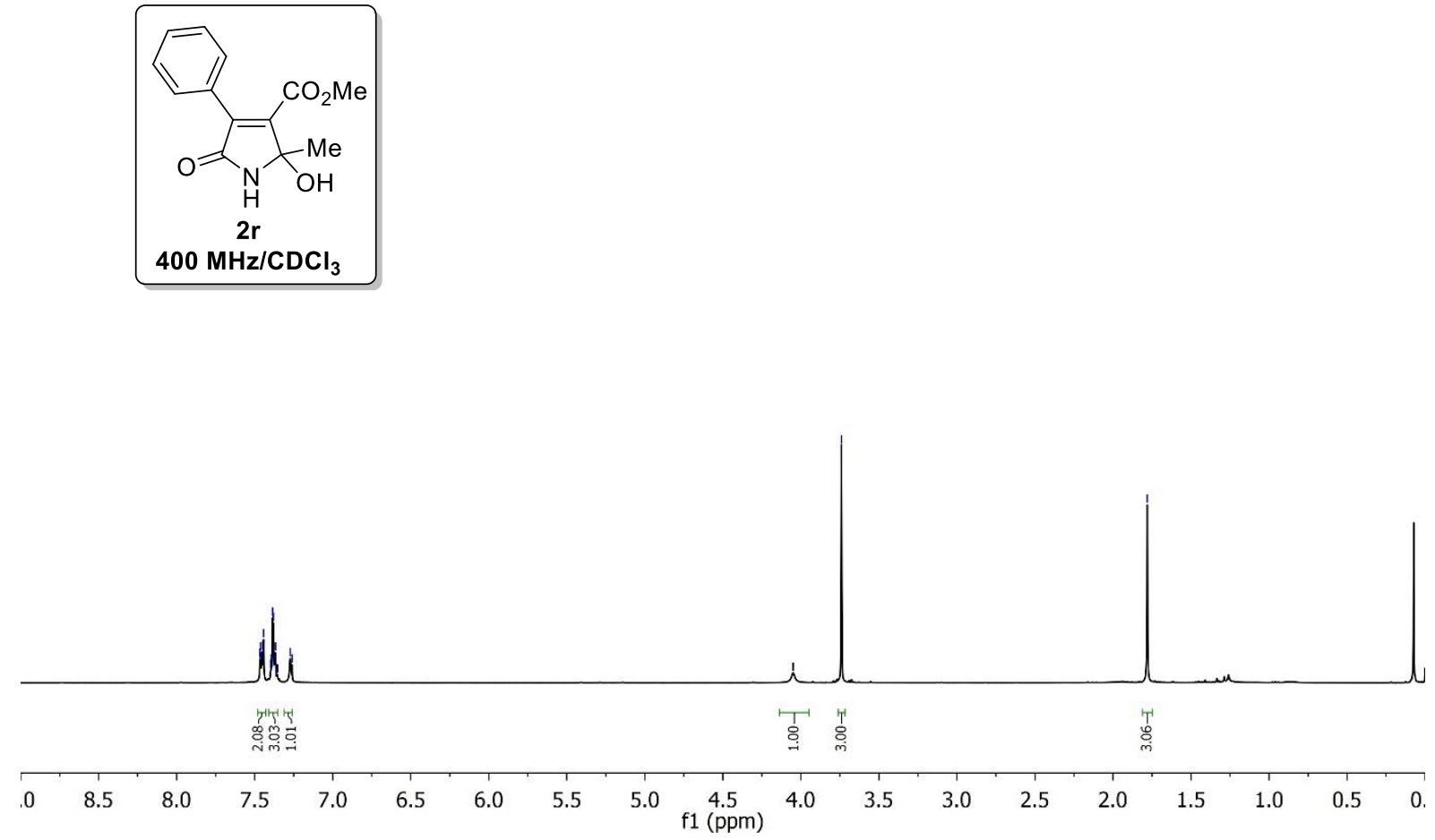

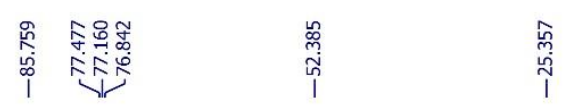

$$
100 \mathrm{MHz} / \mathrm{CDCl}_{3}
$$

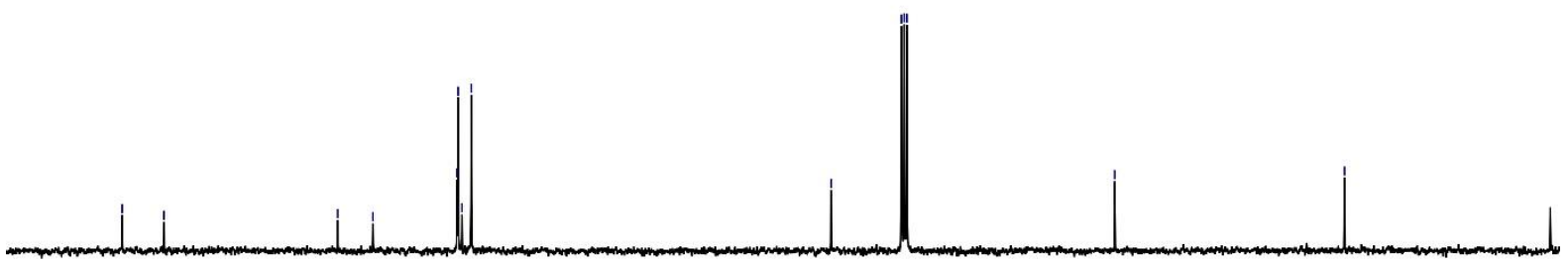

180

$170 \quad 160$

150

$140 \quad 130 \quad 120$

10

$100 \begin{gathered}90 \\ \mathrm{f} 1(\mathrm{ppm})\end{gathered}$

$80 \quad 70$

60

50 

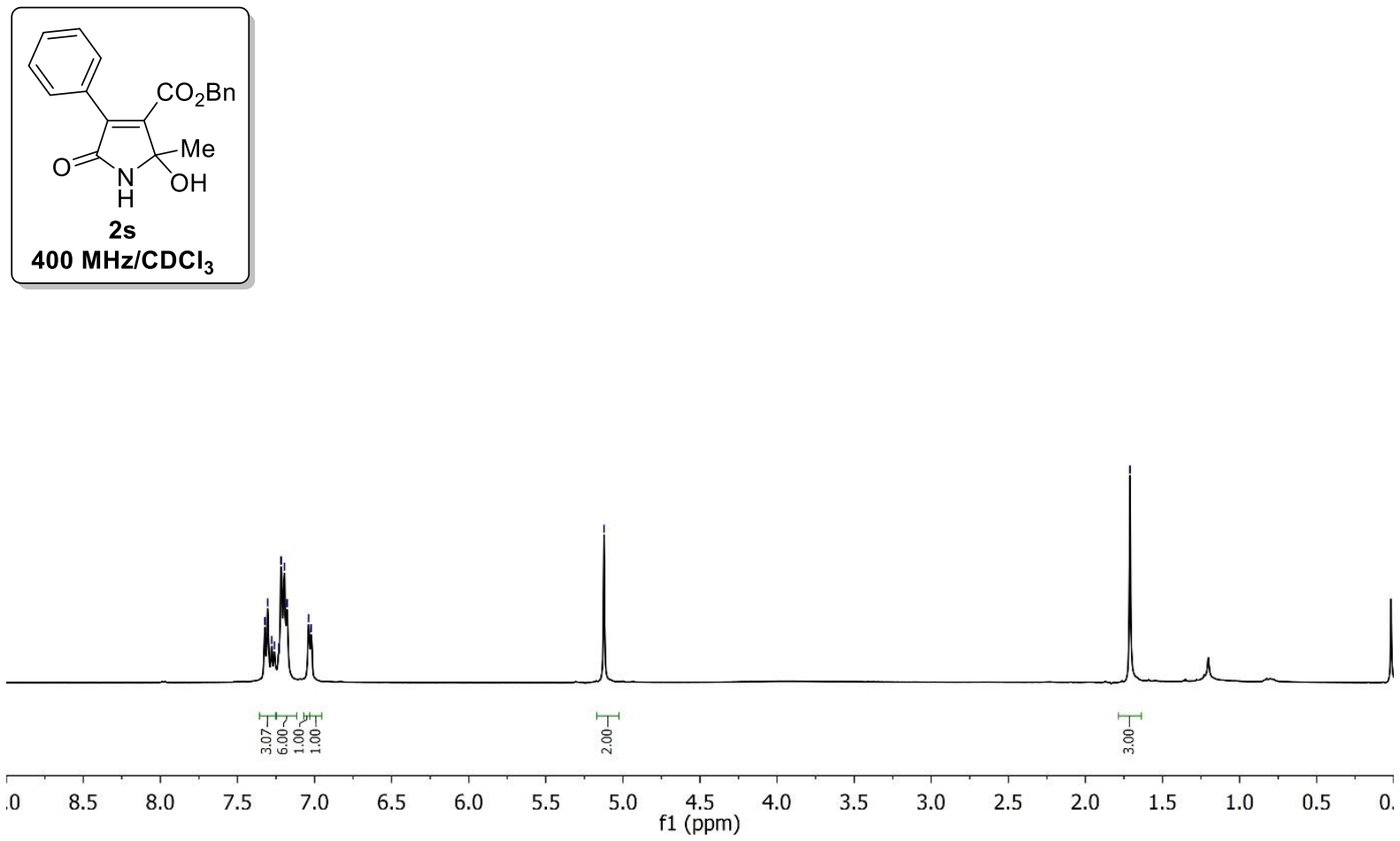

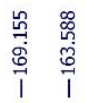
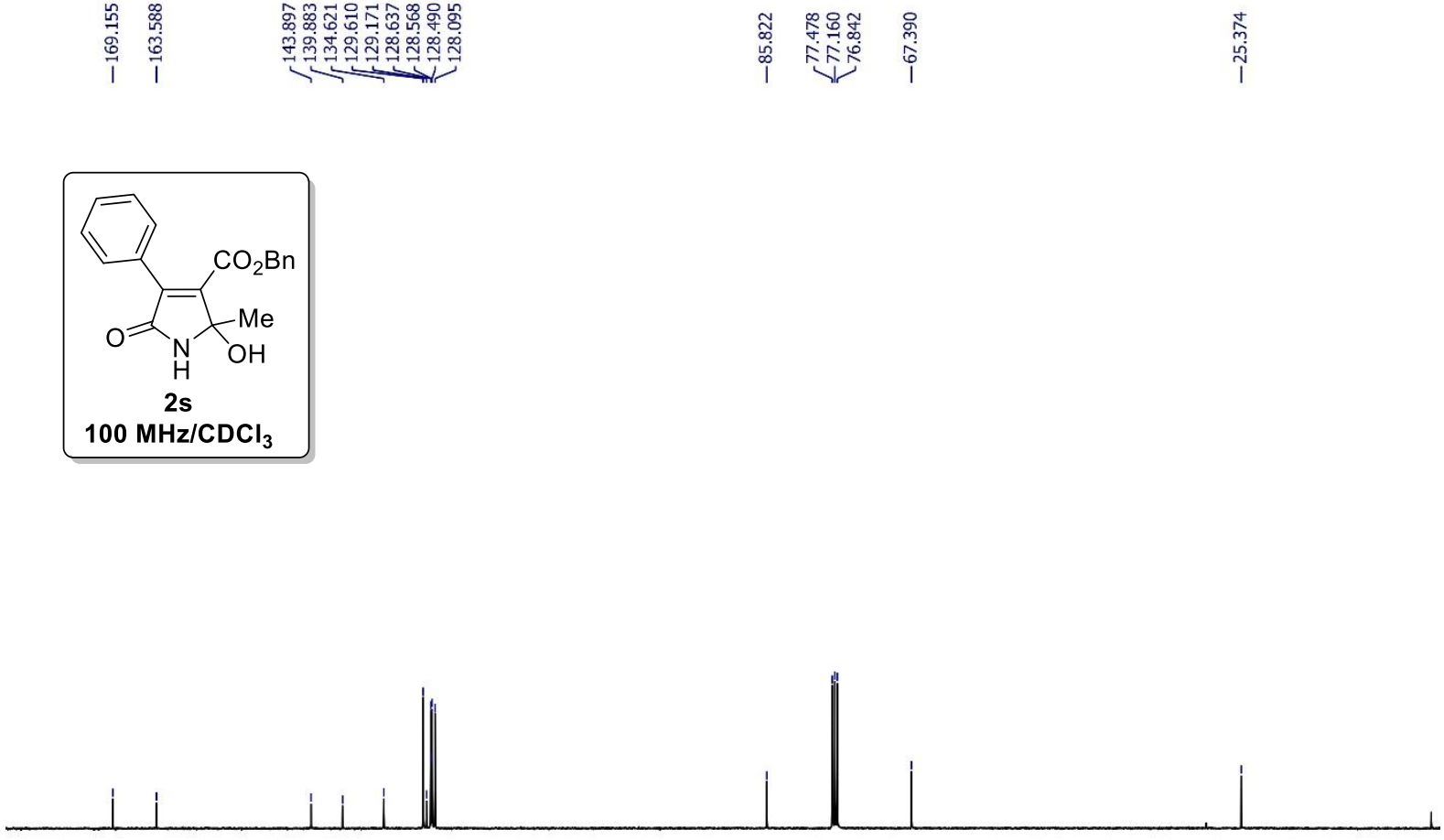

$\begin{array}{rrrr}180 & 170 & 160 & 150\end{array}$

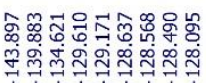

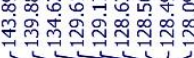

然 占

$120 \quad 110$

$100 \underset{\mathrm{f} 1(\mathrm{ppm})}{90}$

$80 \quad 70 \quad 60$

50

30

$20 \quad 10$ 


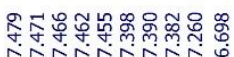
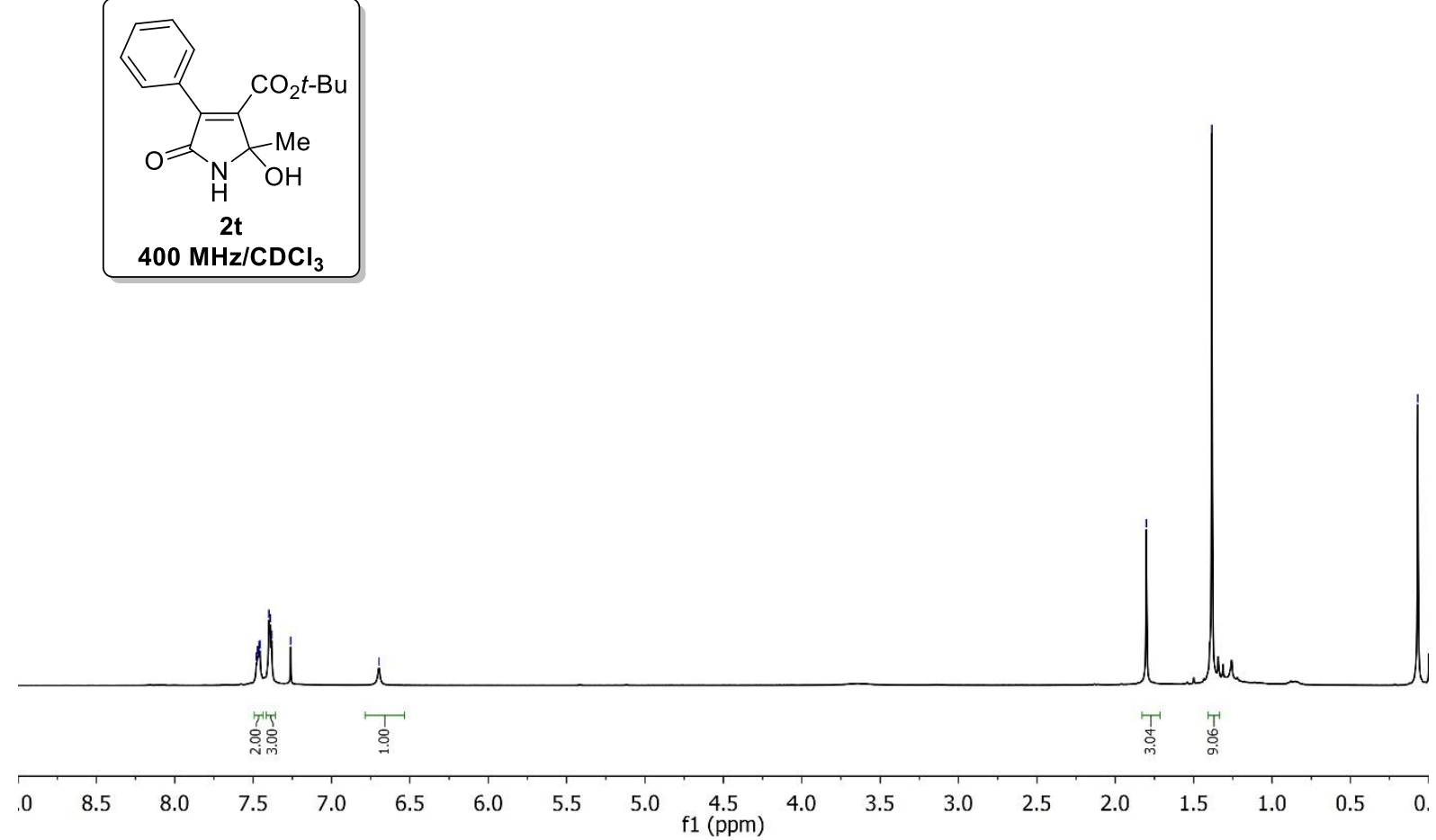

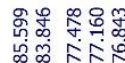

11

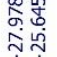

i1

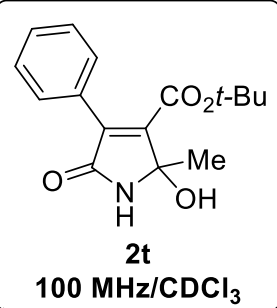



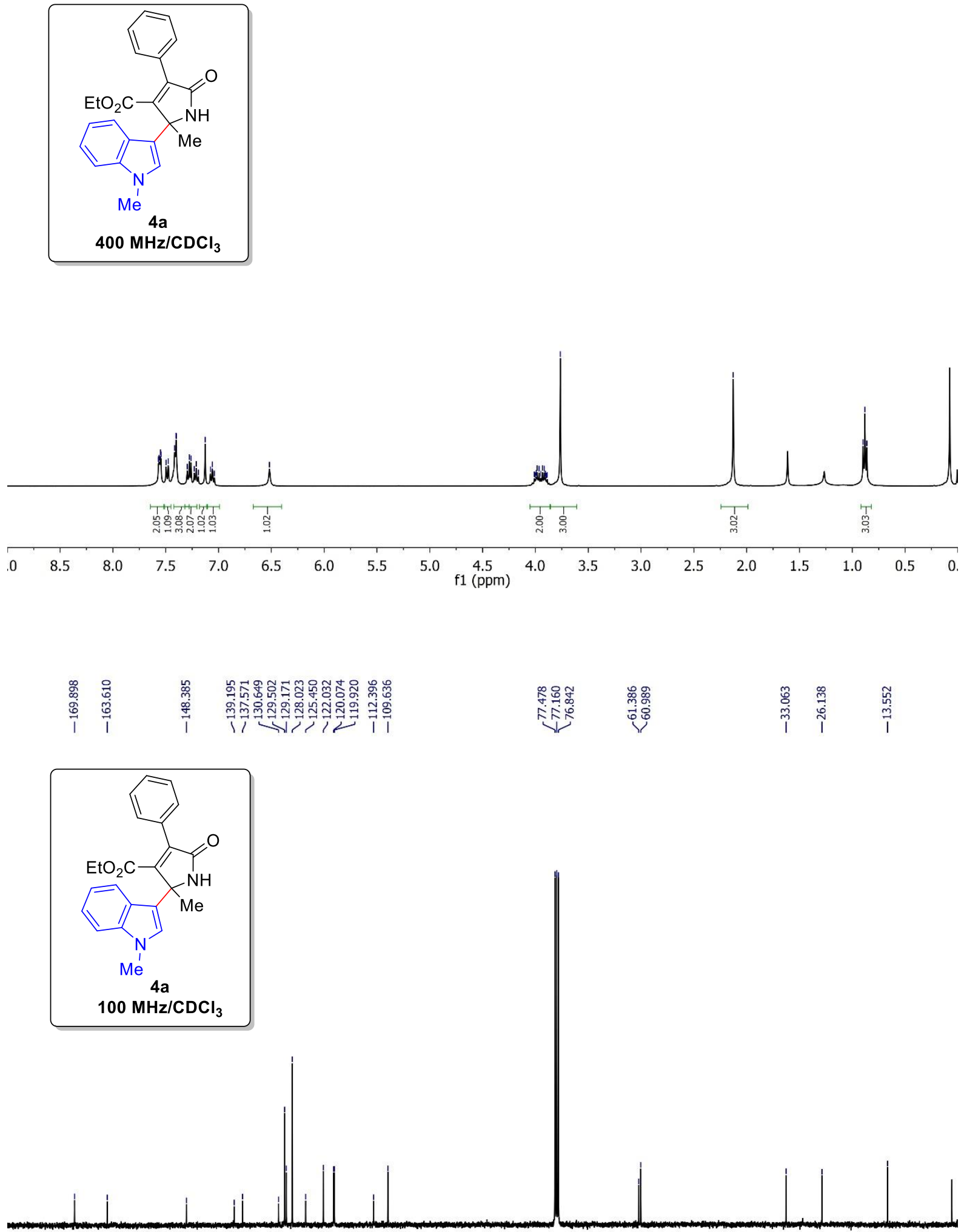

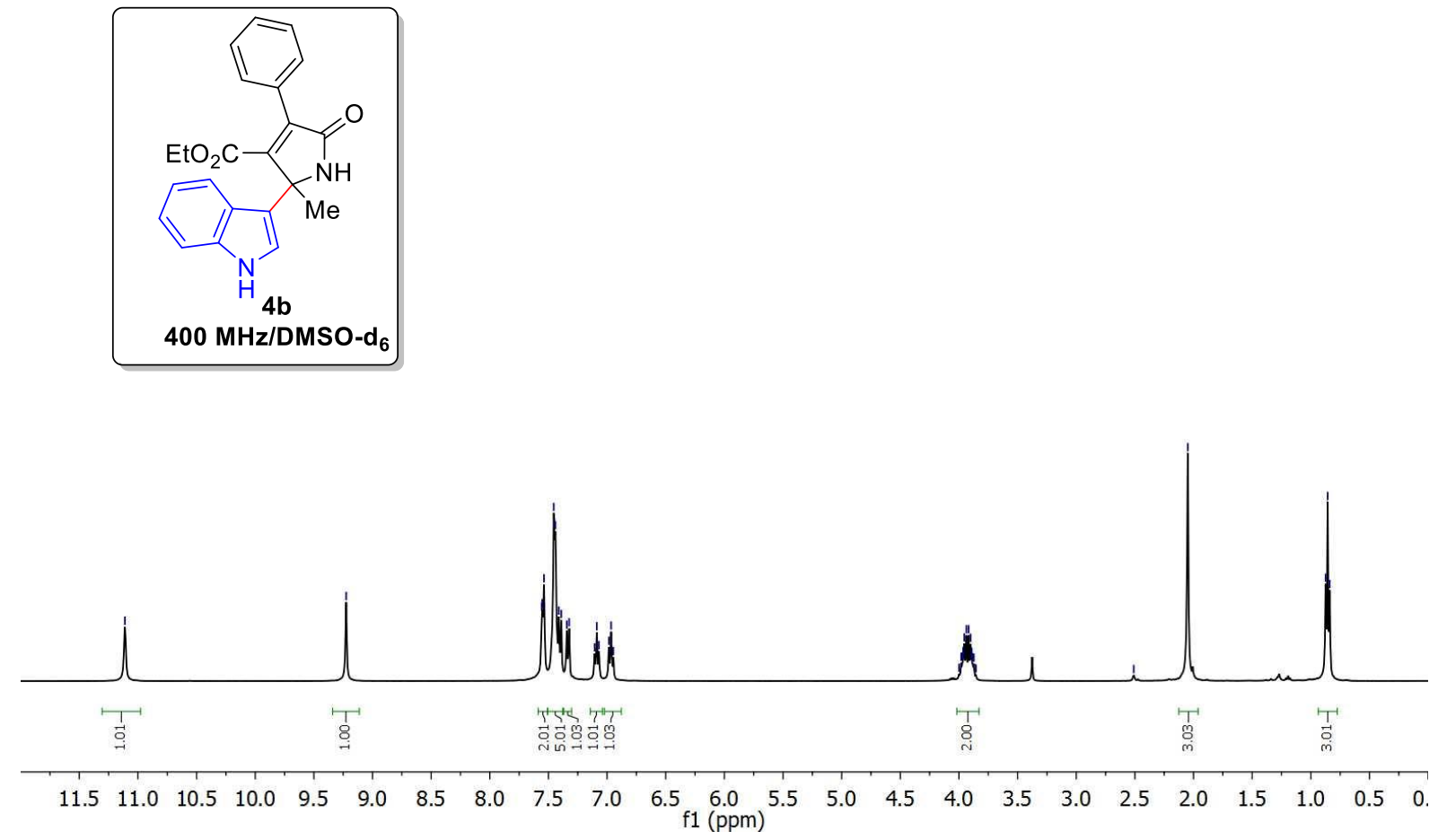

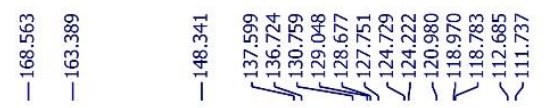
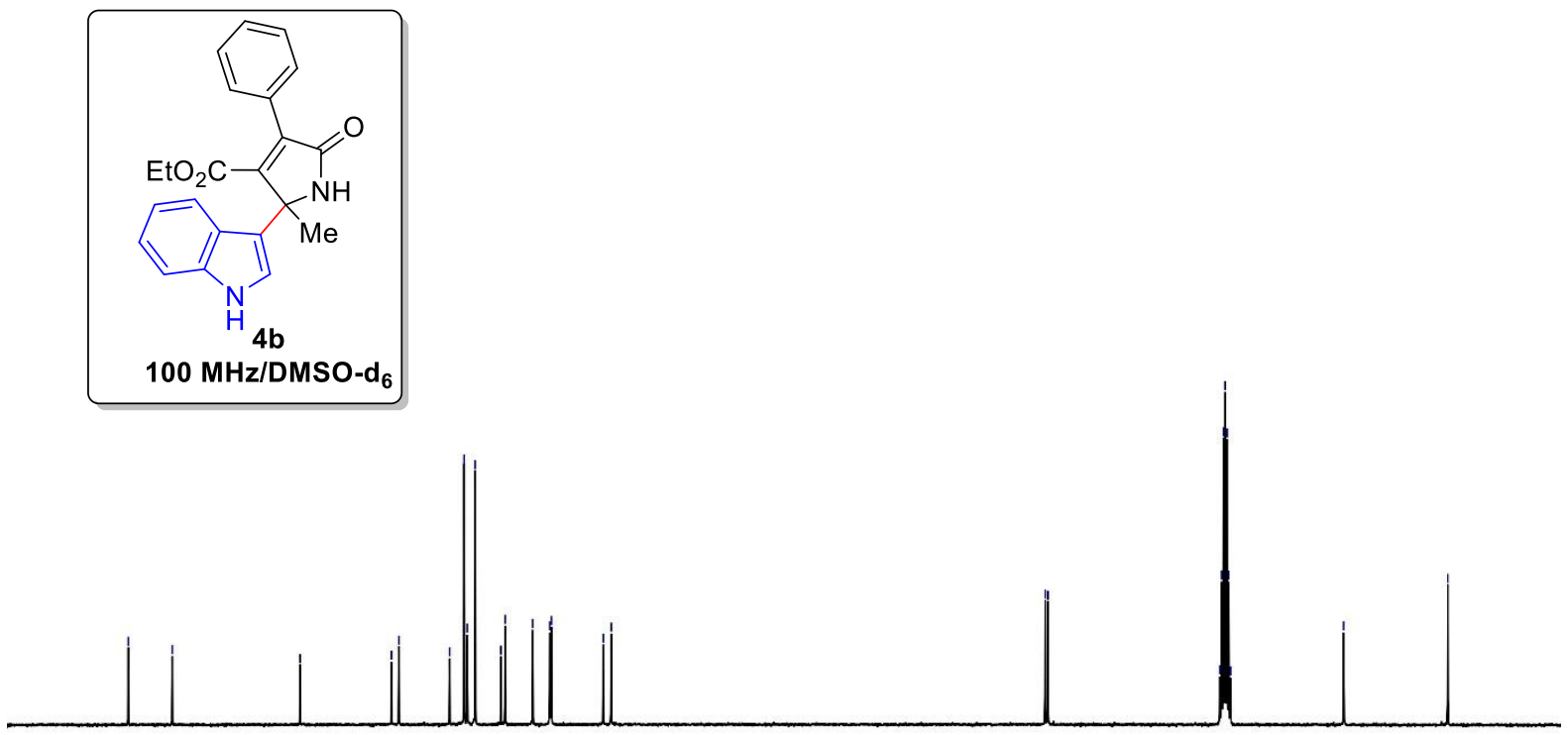

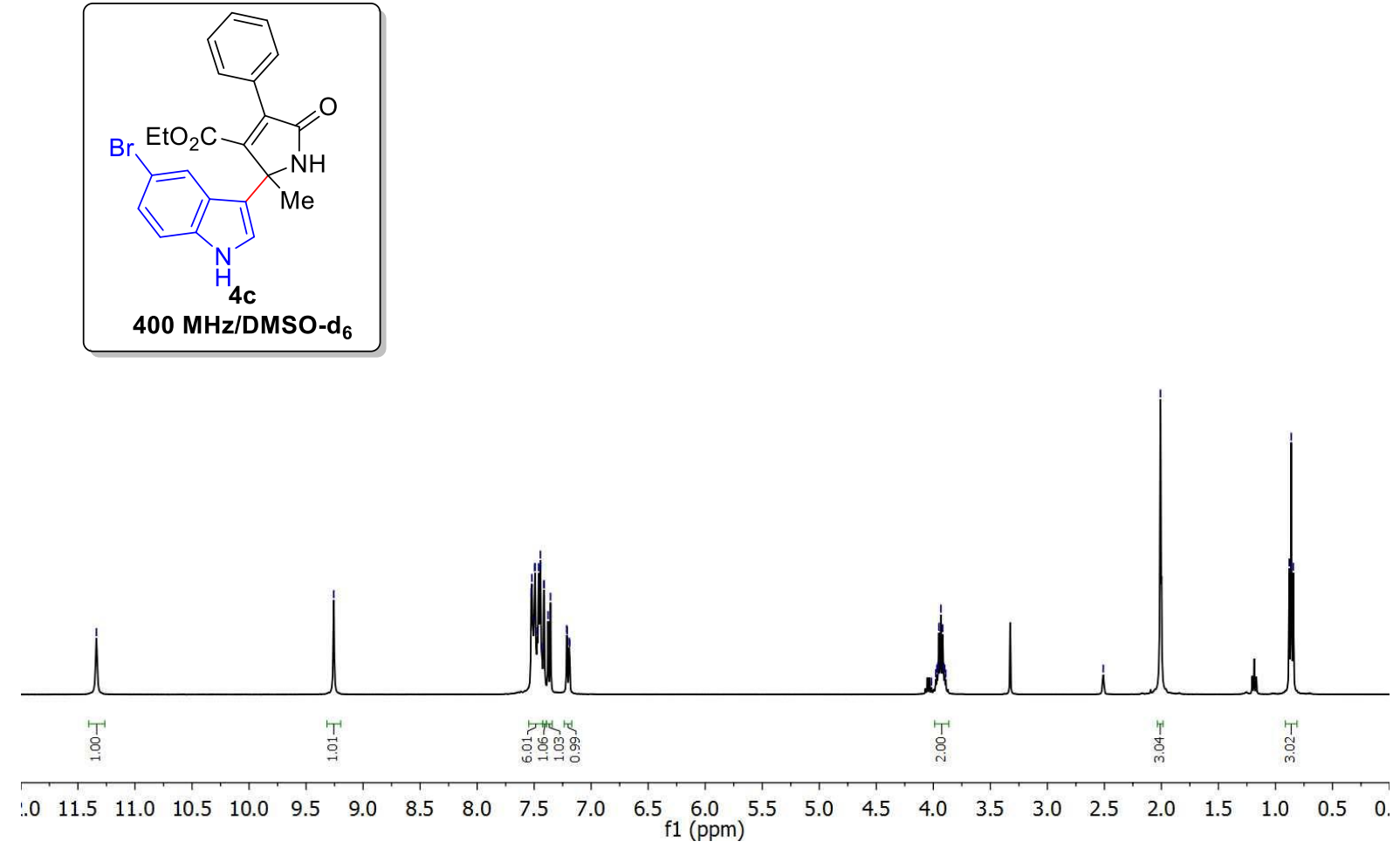

章章

क्ष

泾

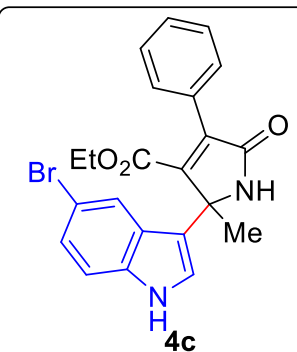

100 MHz/DMSO-d

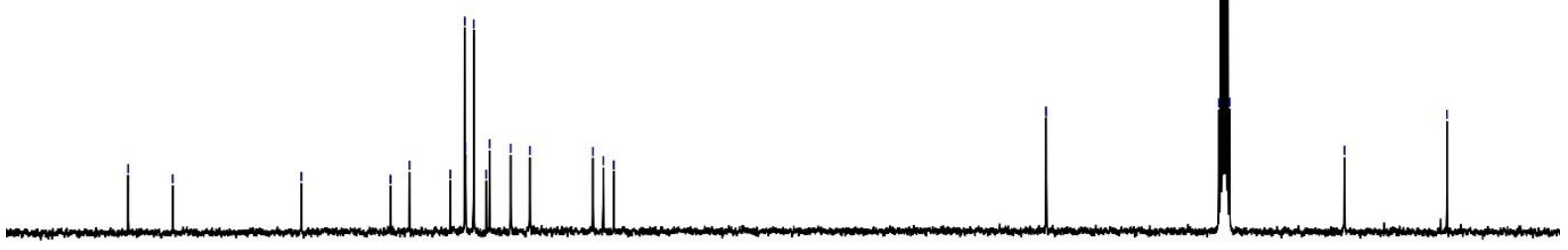

180

$170 \quad 160 \quad 150$

$140 \quad 130$

$120 \quad 110$

$100 \underset{\mathrm{f} 1(\mathrm{ppm})}{90}$

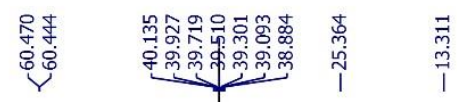



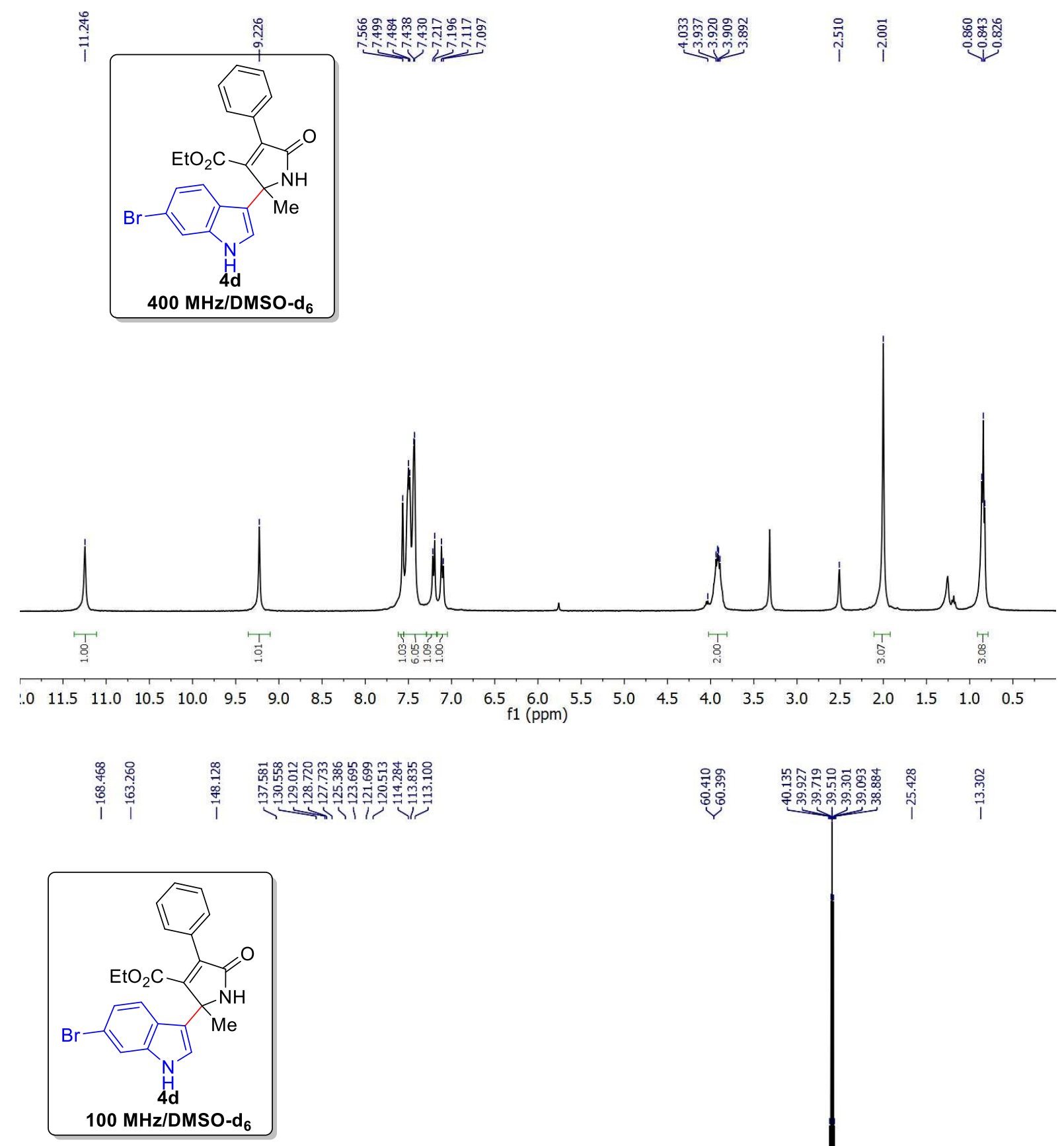

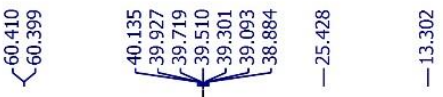

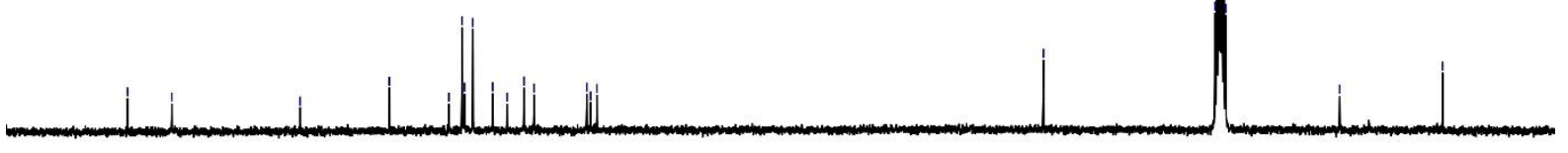

180

$170 \quad 160 \quad 150$

$\begin{array}{llll}140 & 130 & 120 & 110\end{array}$

$100 \underset{\mathrm{f} 1(\mathrm{ppm})}{90}$

$80 \quad 70 \quad 60$

50

$20 \quad 10$ 

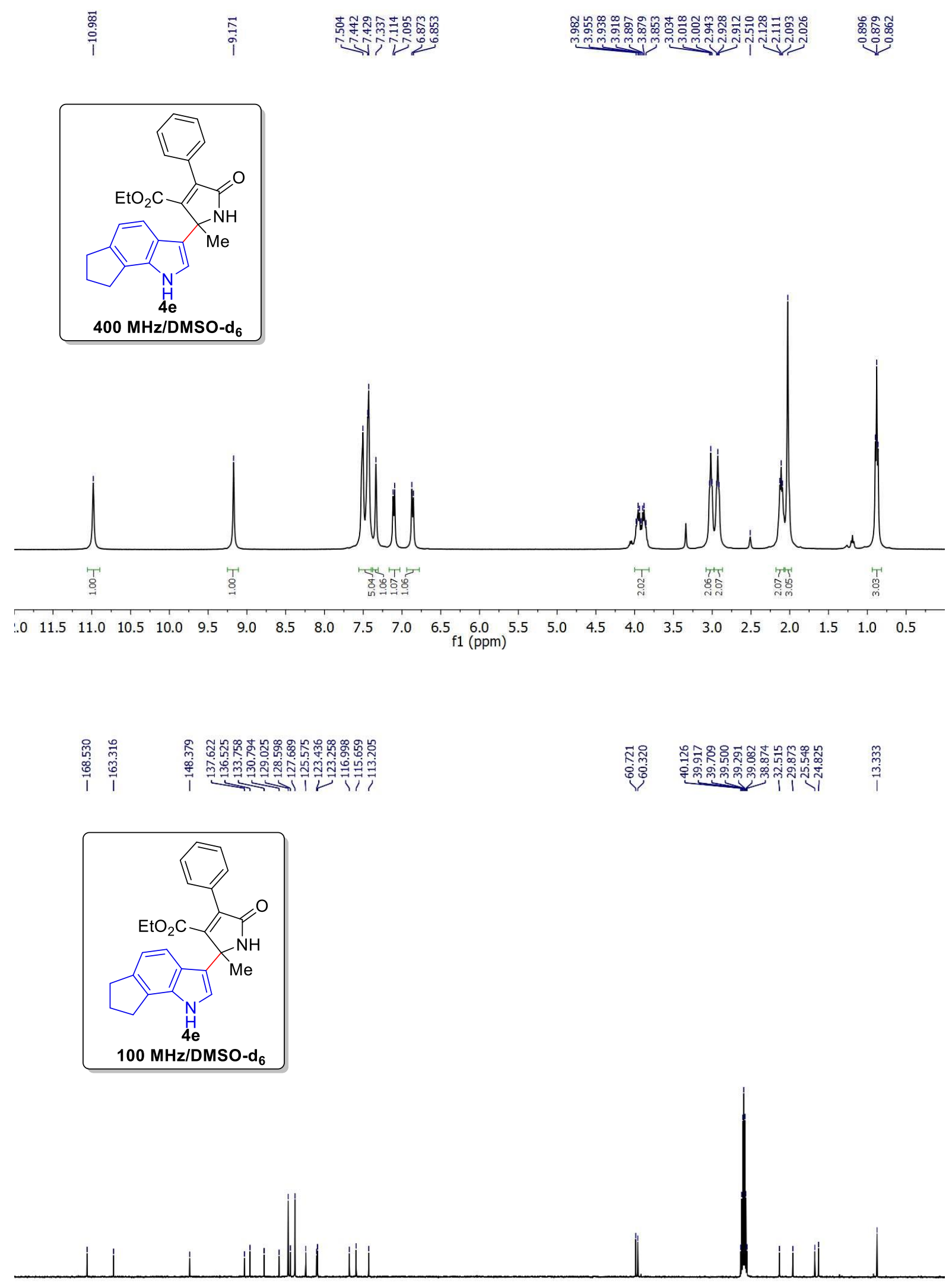

$\begin{array}{rlllllllllllllllll}180 & 170 & 160 & 150 & 140 & 130 & 120 & 110 & 100 \begin{array}{c}90 \\ \mathrm{f} 1(\mathrm{ppm})\end{array} & 80 & 70 & 60 & 50 & 40 & 30 & 20 & 10 & (\end{array}$ 

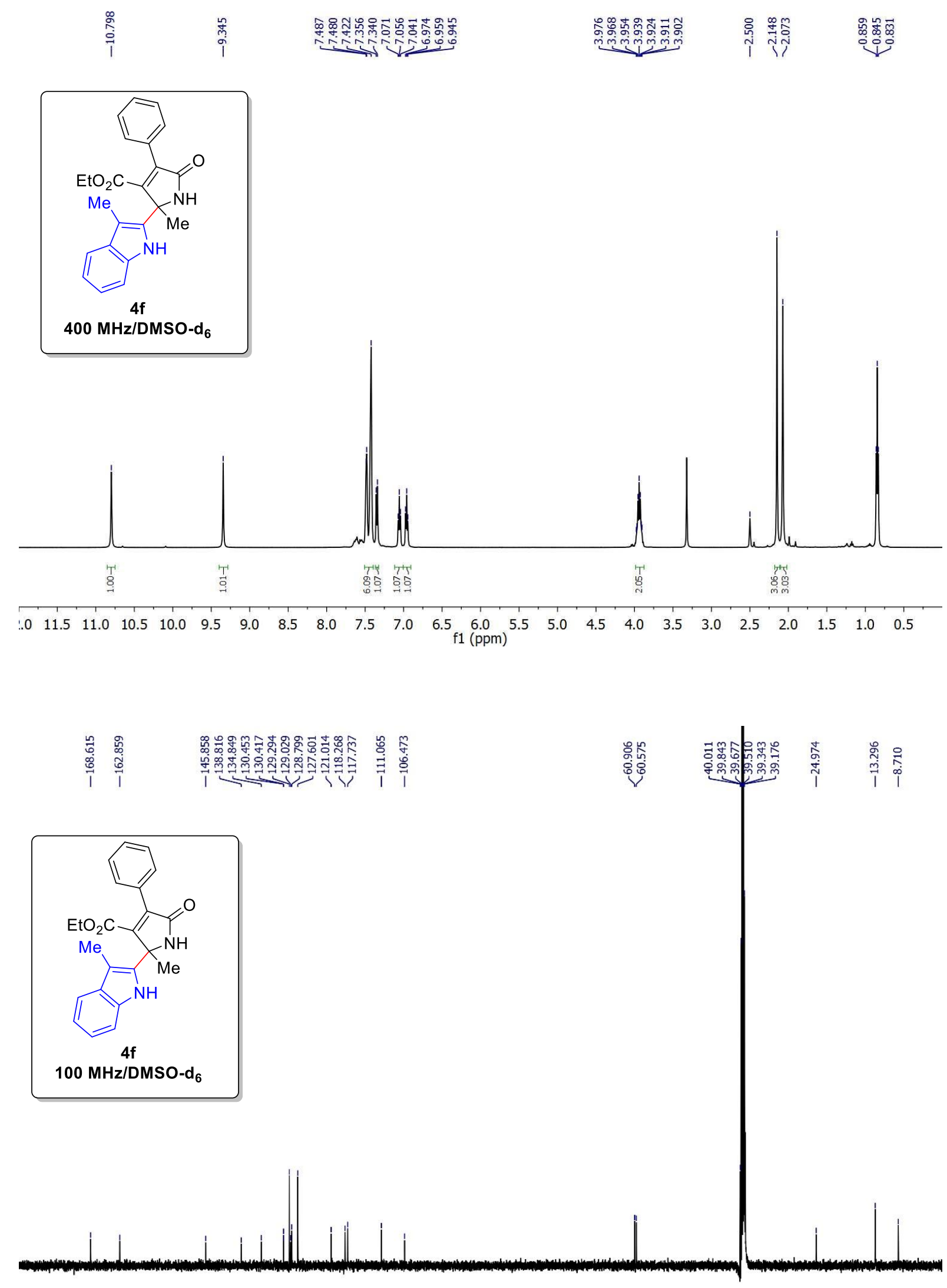

180

$170 \quad 160 \quad 150$

$140 \quad 130$

$120 \quad 110$

$100 \underset{f 1(\mathrm{ppm})}{90} 80 \quad 70 \quad 60$

$\begin{array}{llllll}50 & 40 & 30 & 20 & 10\end{array}$ 

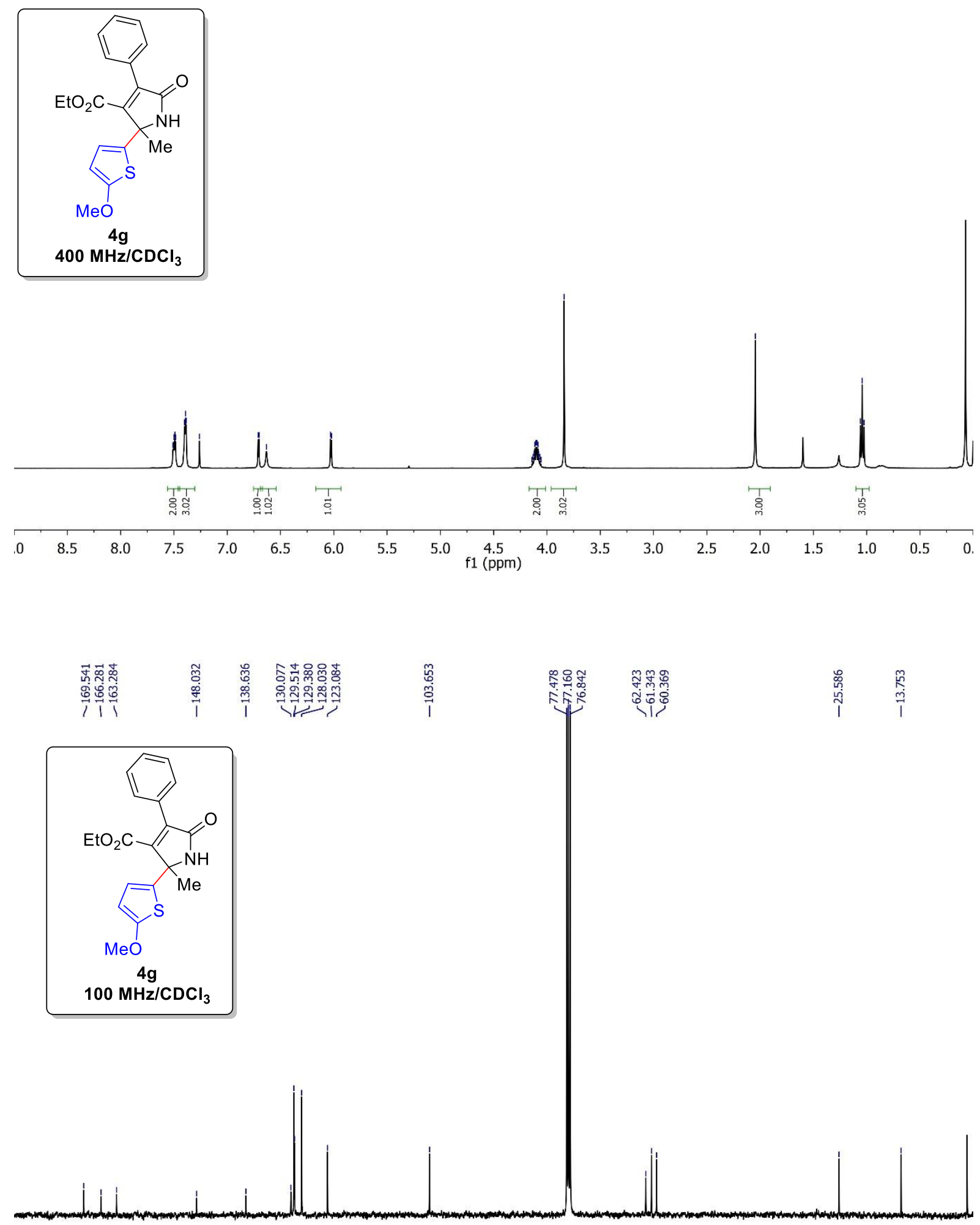

180 


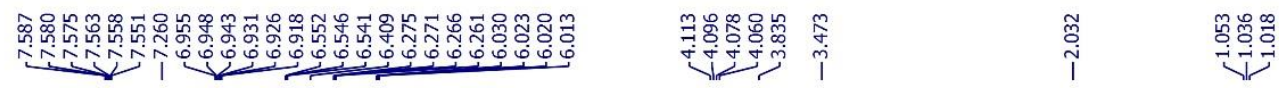
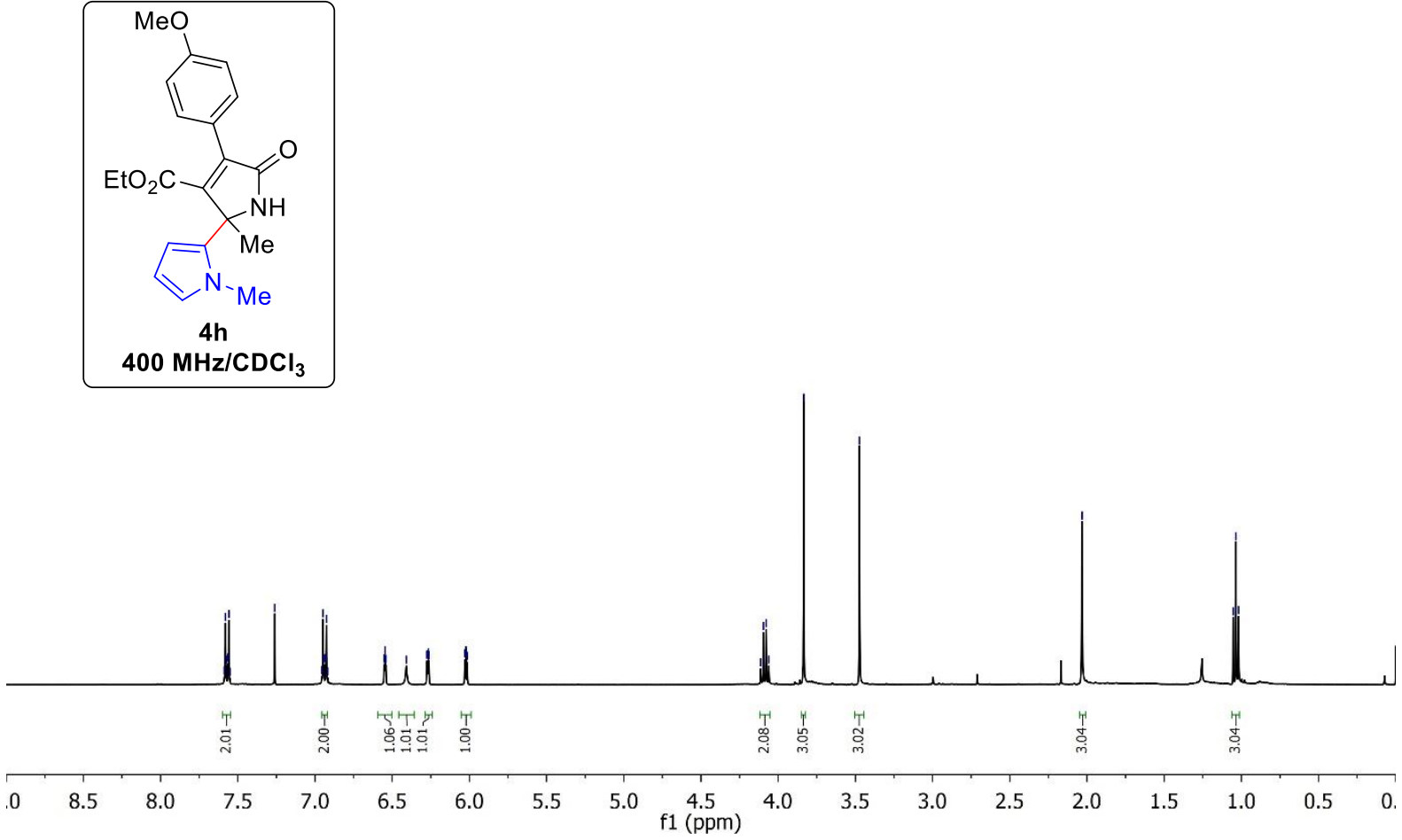

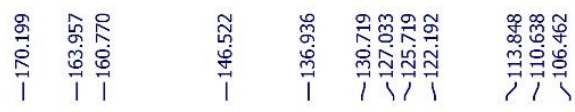

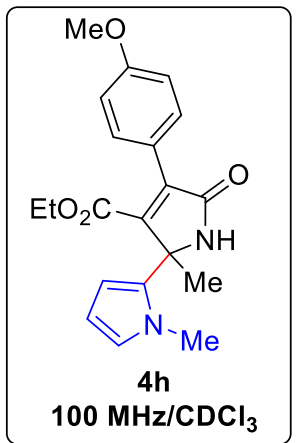

180

$170 \quad 160$

150

140130

120

110

$100 \underset{f 1(p p m)}{90}$

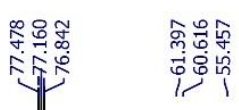

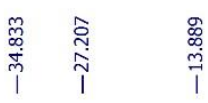

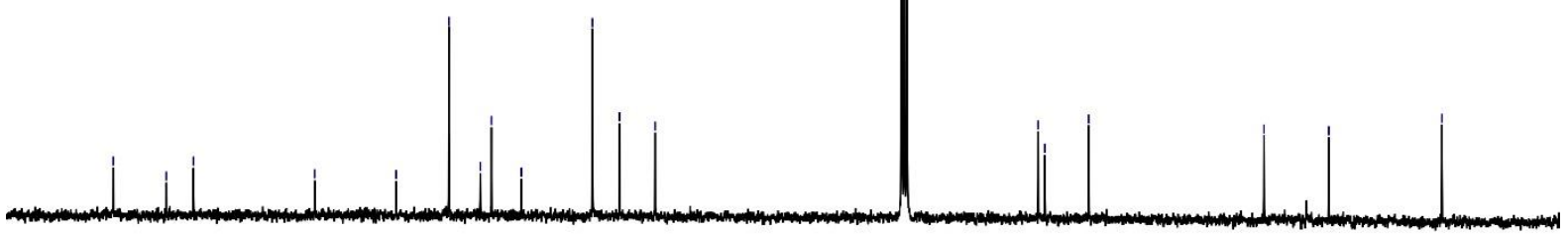




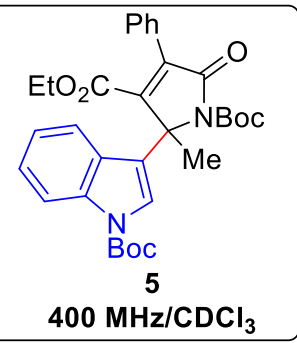

$400{\mathrm{MHz} / \mathrm{CDCl}_{3}}_{3}$

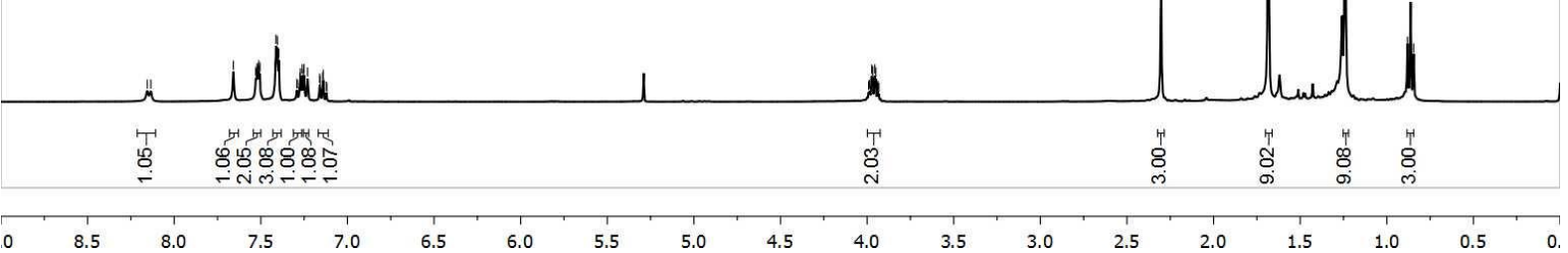

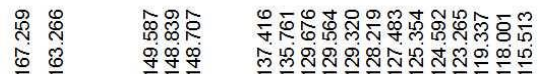

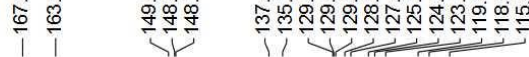

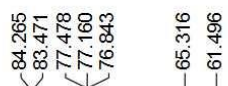

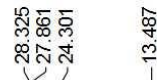
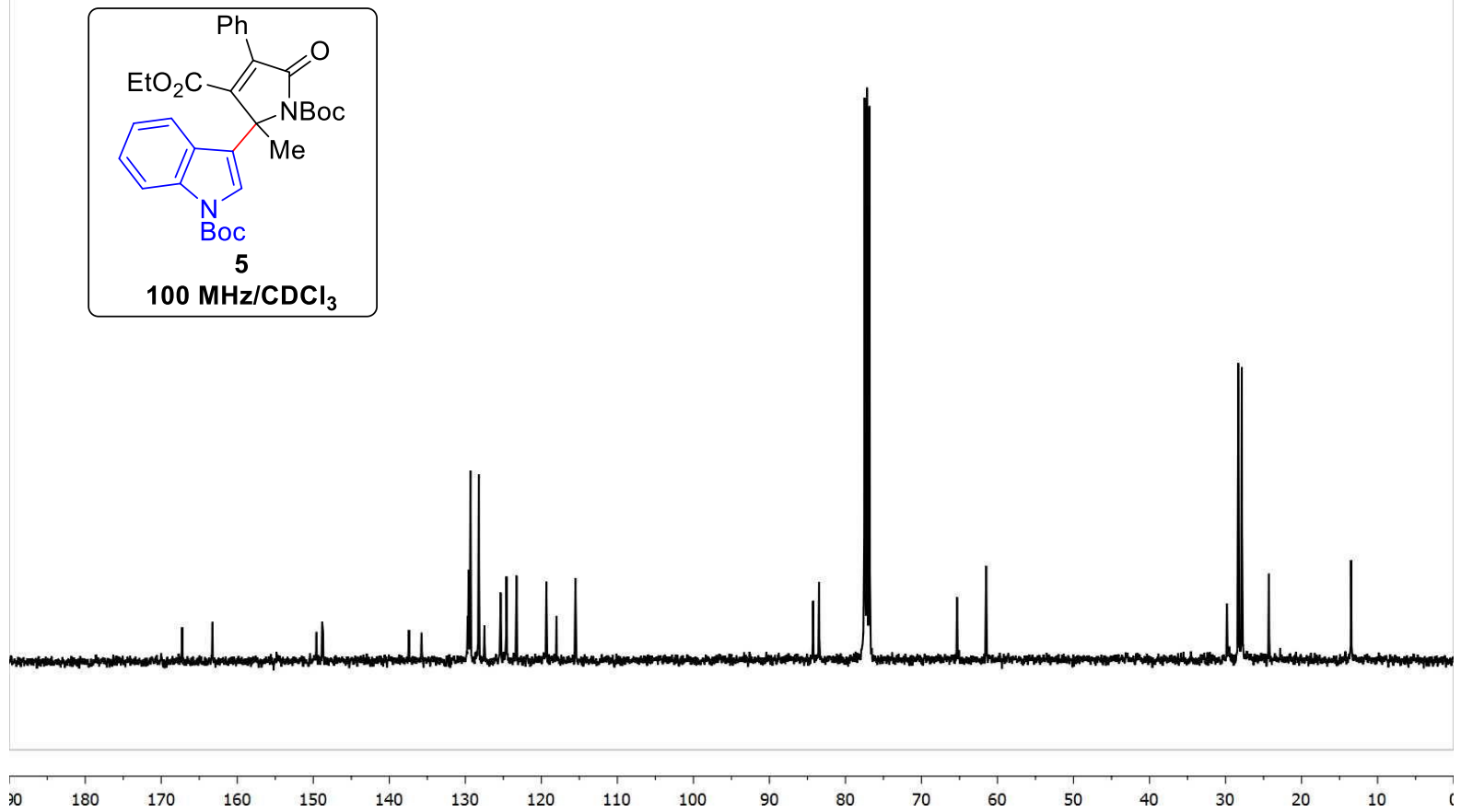

$150 \quad 140$

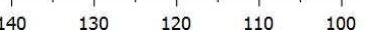
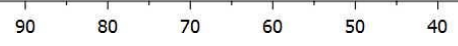

30

101 

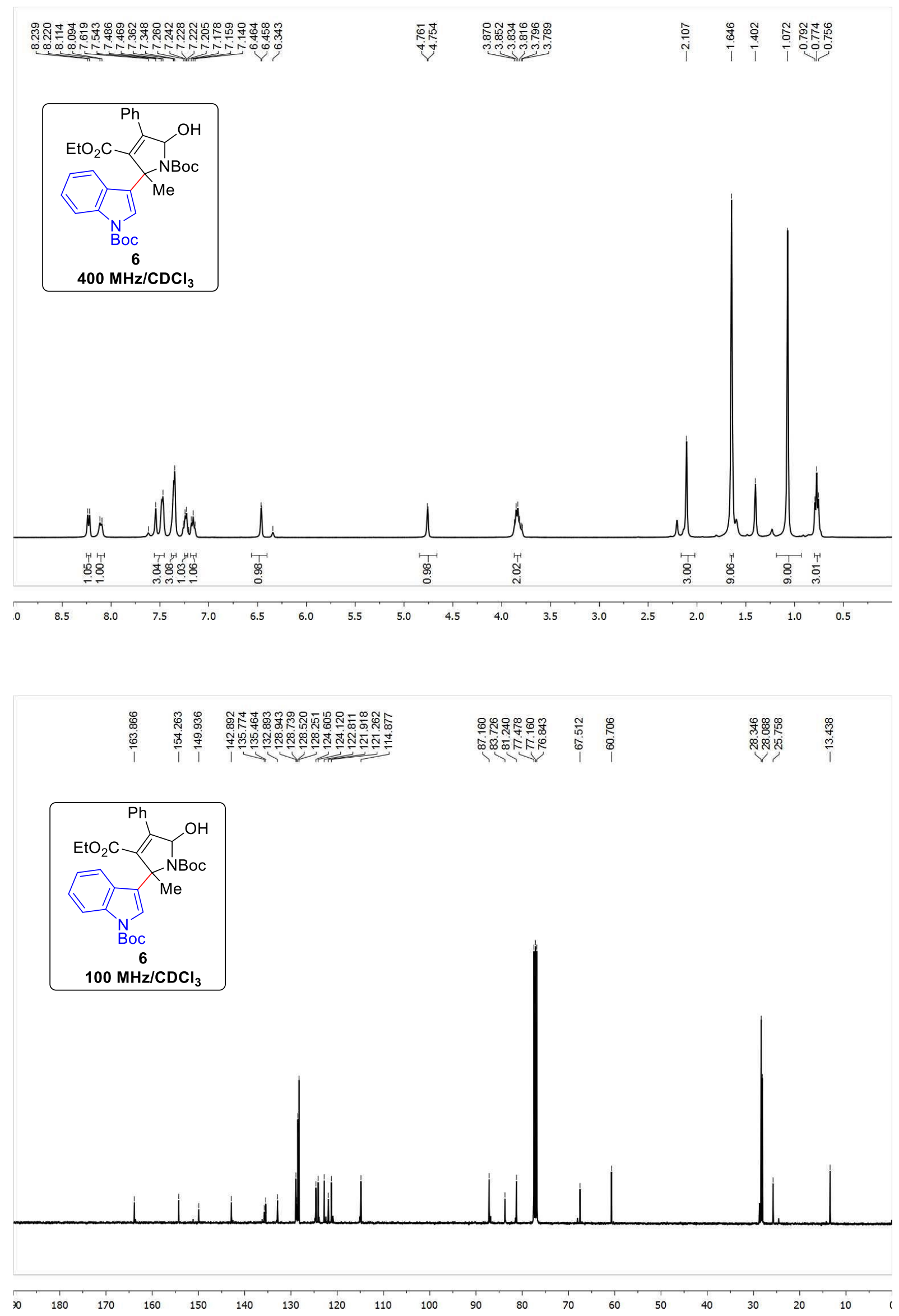

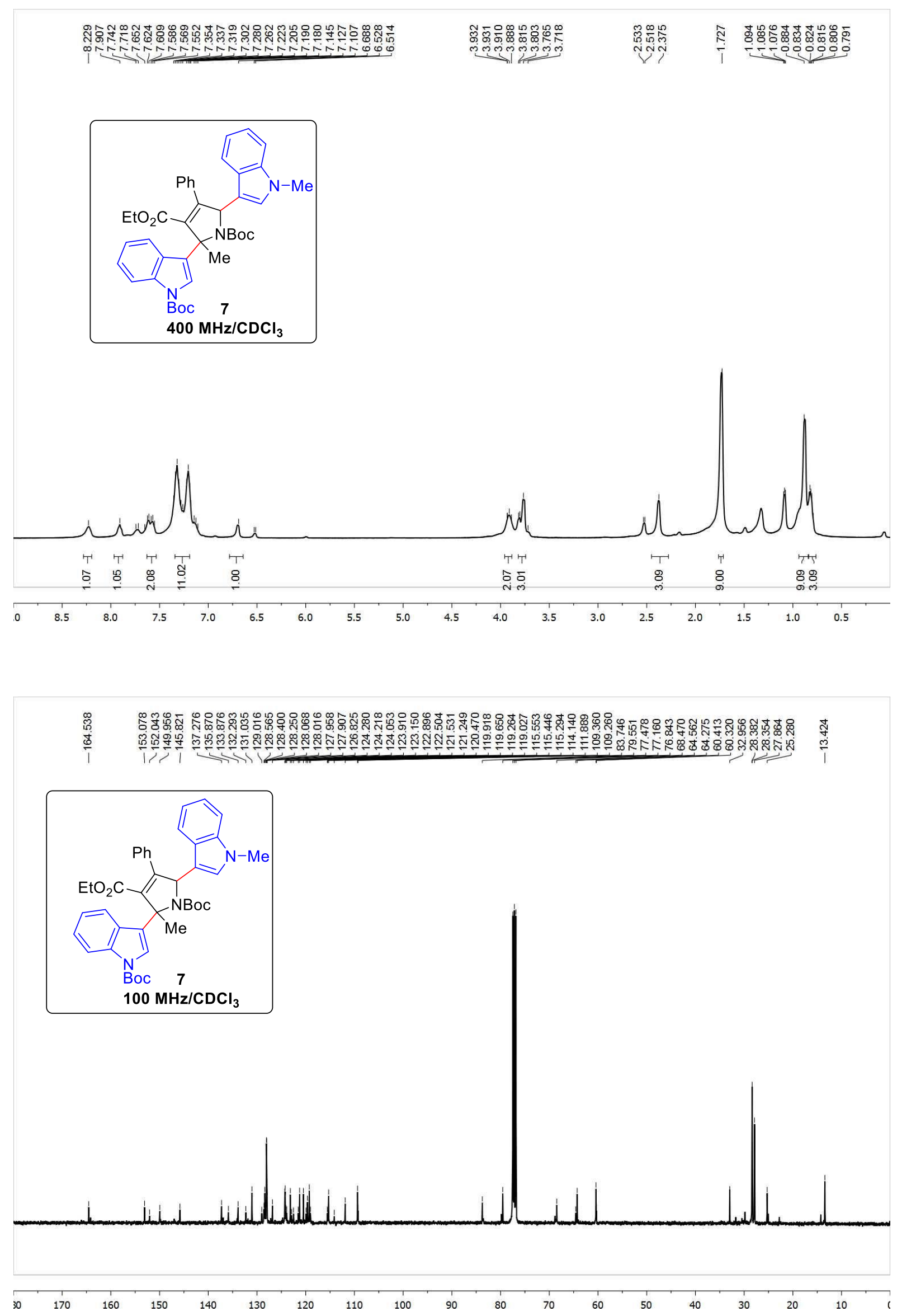


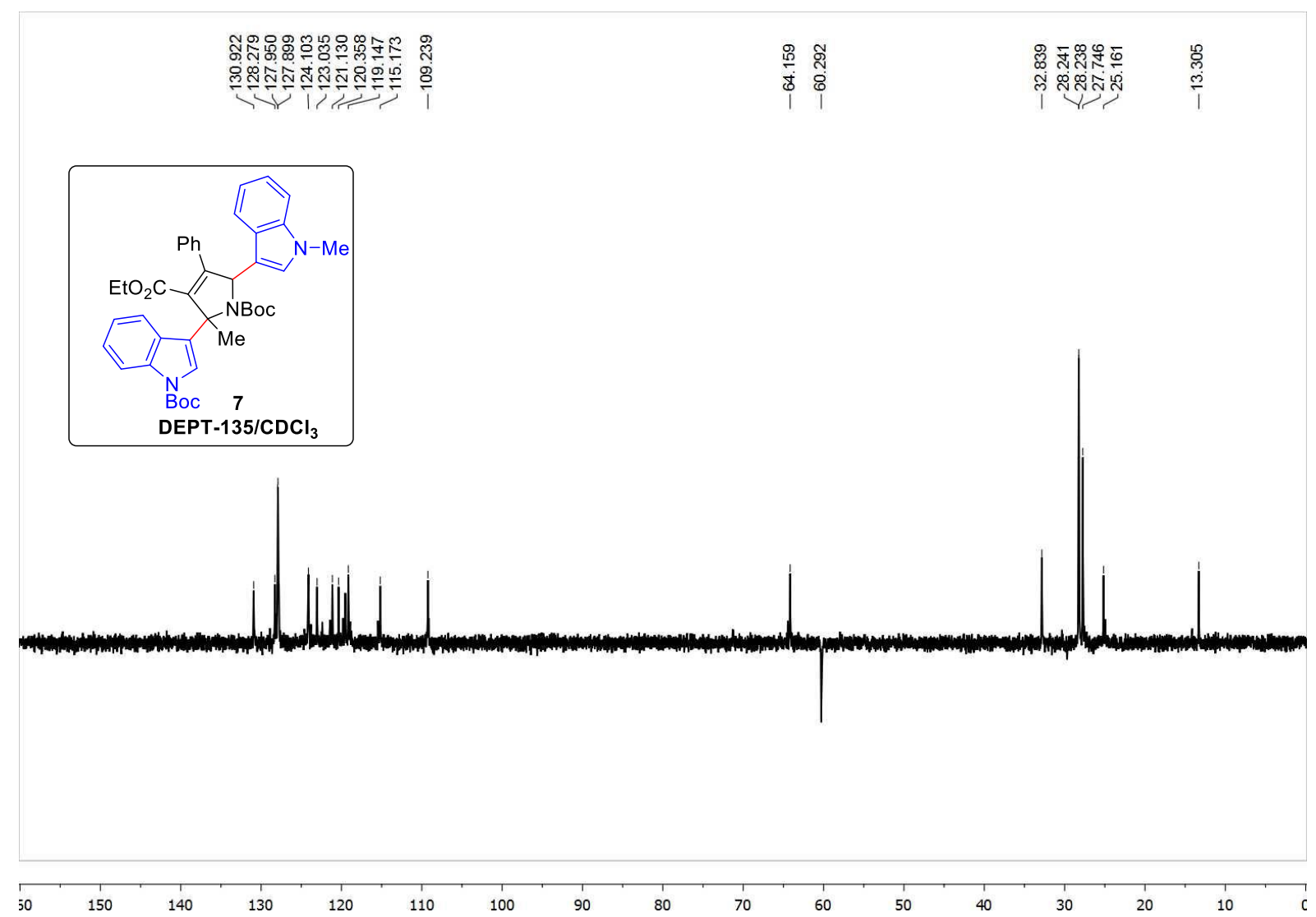

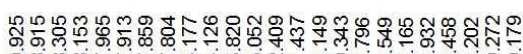

然

$\frac{\sqrt{8}}{\frac{1}{9}}$
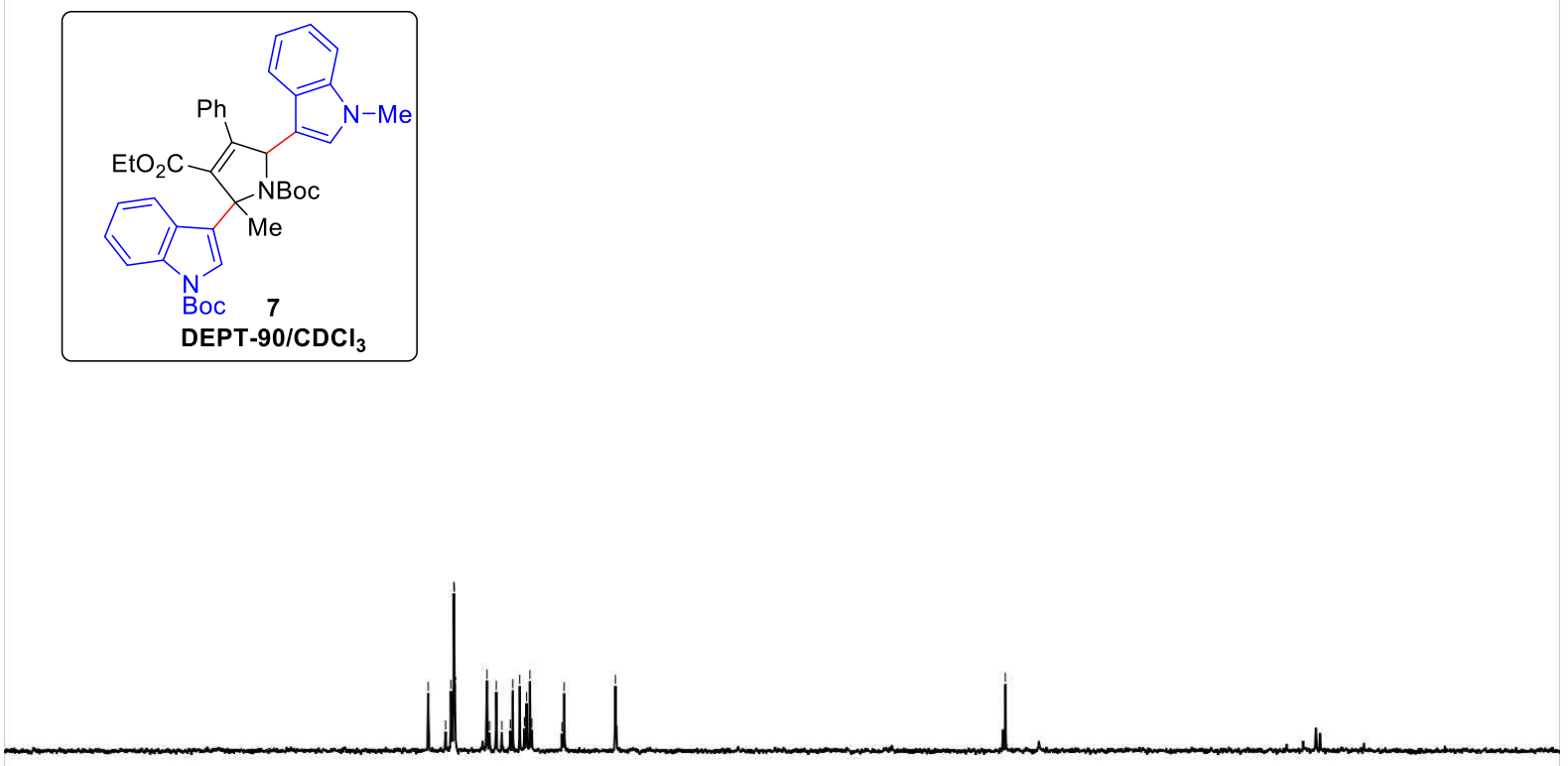

30
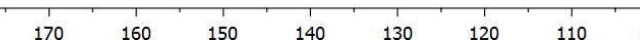

$100 \quad 90$
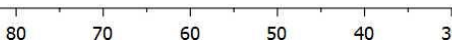

20,10, 


\section{告}

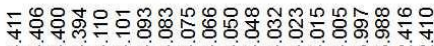

4riturututum

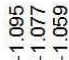
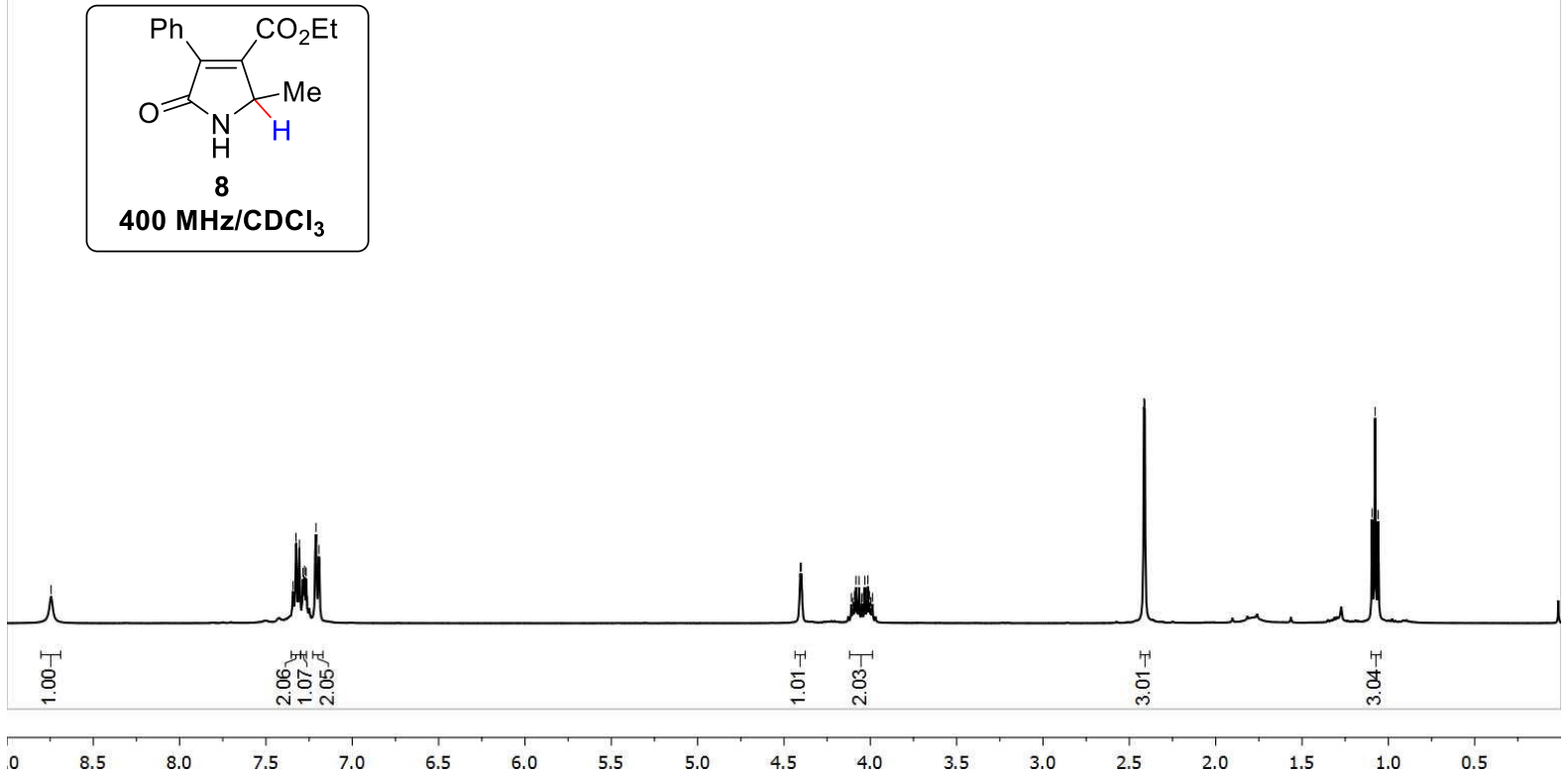

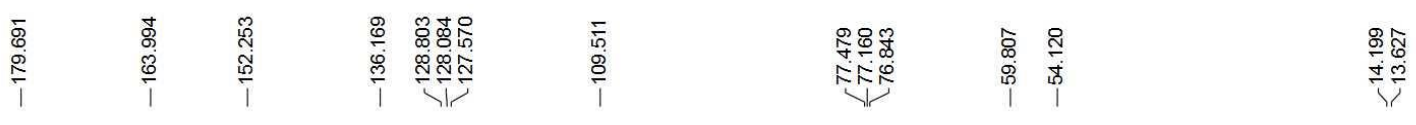

$$
100 \mathrm{MHz} / \mathrm{CDCl}_{3}
$$

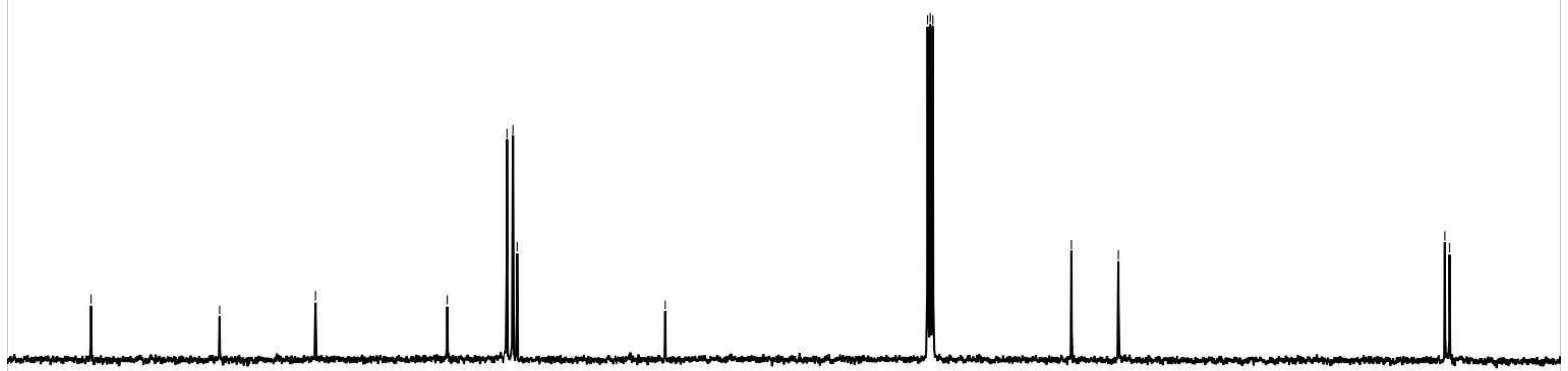

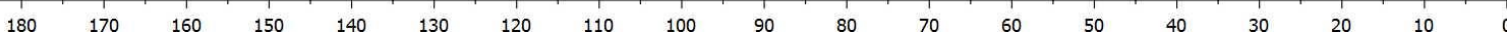




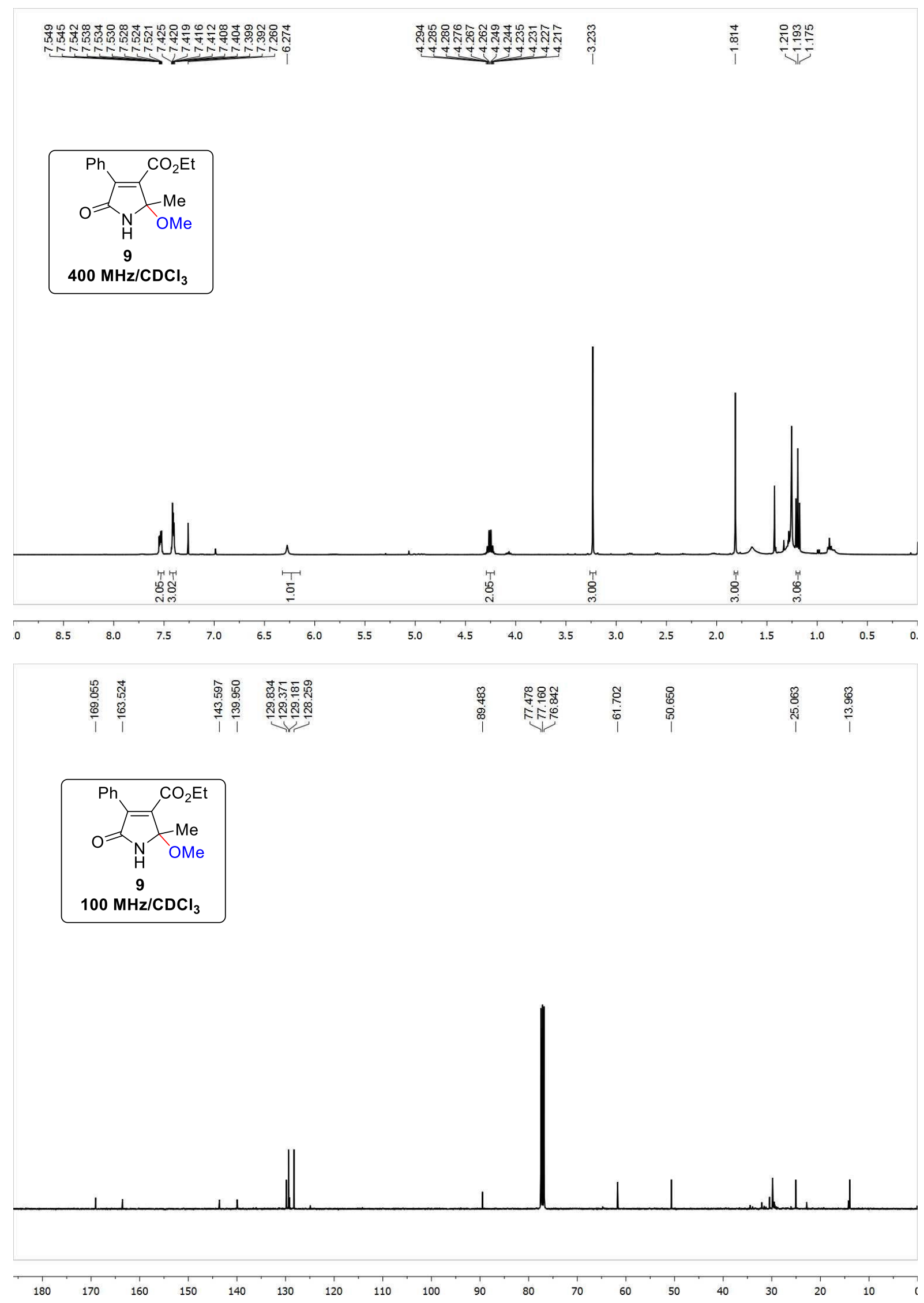



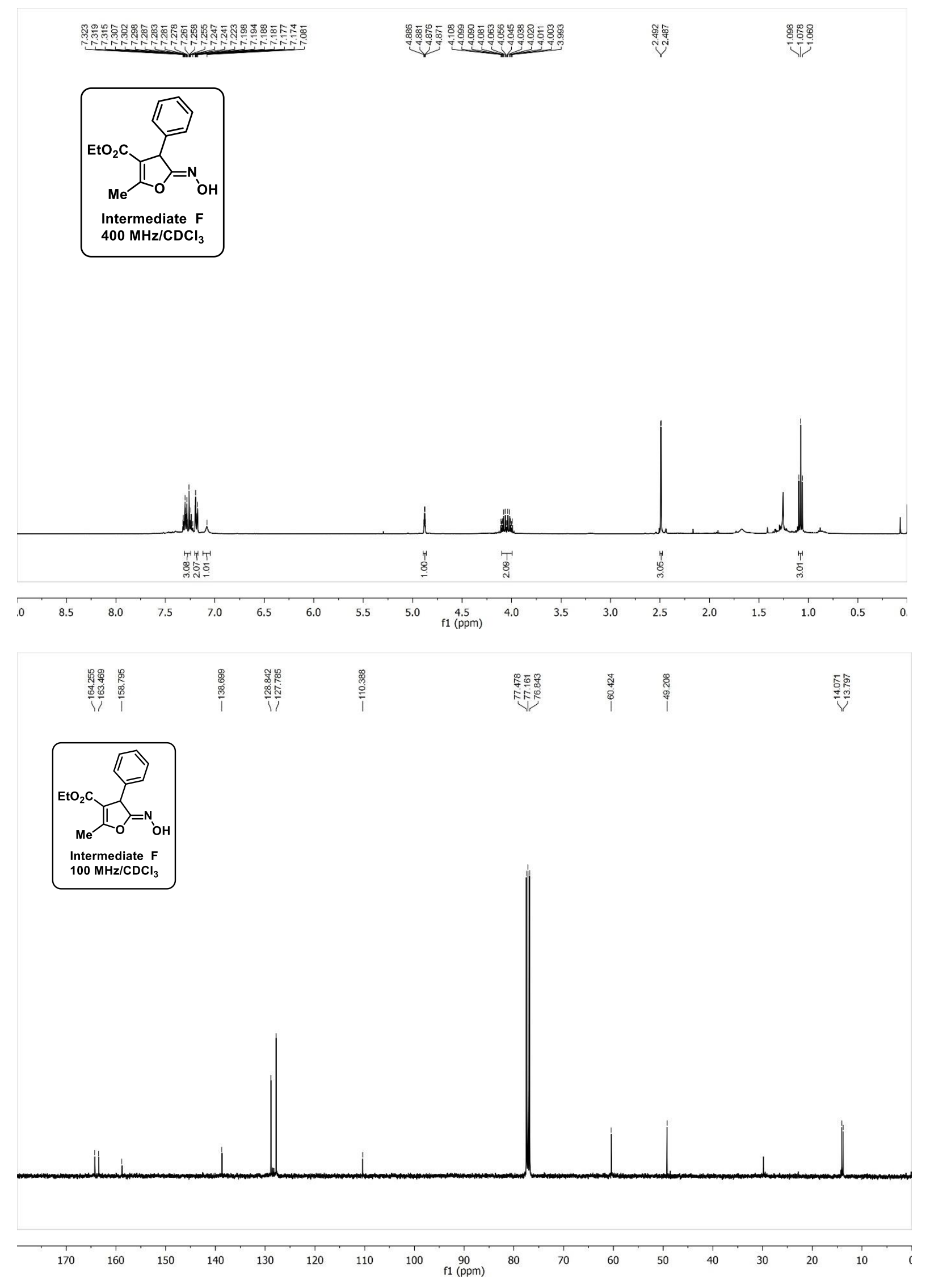